Check for updates

Cite this: Phys. Chem. Chem. Phys., 2018, 20, 3128

\title{
Protonation/reduction dynamics at the [4Fe-4S] cluster of the hydrogen-forming cofactor in [FeFe]-hydrogenases $\dagger$
}

\author{
Moritz Senger, (D) ${ }^{a}$ Stefan Mebs, (D) ${ }^{b}$ Jifu Duan, (D) ${ }^{c}$ Olga Shulenina, ${ }^{d}$ \\ Konstantin Laun, ${ }^{a}$ Leonie Kertess, iD ' Florian Wittkamp, ${ }^{e}$ Ulf-Peter Apfel, \\ Thomas Happe, ${ }^{c}$ Martin Winkler, ${ }^{* c}$ Michael Haumann*b ${ }^{*}$ and Sven T. Stripp (DD *a
}

\begin{abstract}
The [FeFe]-hydrogenases of bacteria and algae are the most efficient hydrogen conversion catalysts in nature. Their active-site cofactor $(\mathrm{H}$-cluster) comprises a [4Fe-4S] cluster linked to a unique diiron site that binds three carbon monoxide $(\mathrm{CO})$ and two cyanide $\left(\mathrm{CN}^{-}\right)$ligands. Understanding microbial hydrogen conversion requires elucidation of the interplay of proton and electron transfer events at the $\mathrm{H}$-cluster. We performed real-time spectroscopy on [FeFe]-hydrogenase protein films under controlled variation of atmospheric gas composition, sample $\mathrm{pH}$, and reductant concentration. Attenuated total reflection Fourier-transform infrared spectroscopy was used to monitor shifts of the $\mathrm{CO} / \mathrm{CN}^{-}$vibrational bands in response to redox and protonation changes. Three different [FeFe]-hydrogenases and several protein and cofactor variants were compared, including element and isotopic exchange studies. A protonated equivalent $(\mathbf{H o x H})$ of the oxidized state $(\mathbf{H o x})$ was found, which preferentially accumulated at acidic $\mathrm{pH}$ and under reducing conditions. We show that the one-electron reduced state Hred' represents an intrinsically protonated species. Interestingly, the formation of $\mathbf{H o x H}$ and $\mathbf{H r e d}^{\prime}$ was independent of the established proton pathway to the diiron site. Quantum chemical calculations of the respective $\mathrm{CO} / \mathrm{CN}^{-}$ infrared band patterns favored a cysteine ligand of the [4Fe-4S] cluster as the protonation site in $\mathbf{H o x H}$ and Hred'. We propose that proton-coupled electron transfer facilitates reduction of the [4Fe-4S] cluster and prevents premature formation of a hydride at the catalytic diiron site. Our findings imply that protonation events both at the [4Fe-4S] cluster and at the diiron site of the $\mathrm{H}$-cluster are important in the hydrogen conversion reaction of [FeFe]-hydrogenases.
\end{abstract}

Received 14th July 2017, Accepted 29th August 2017

DOI: $10.1039 / \mathrm{c} 7 \mathrm{cp} 04757 f$

rsc.li/pccp

\section{Introduction}

Hydrogenases are enzymes that catalyze hydrogen conversion in archaea, bacteria, fungi, and algae. ${ }^{1}$ Among the three types of hydrogenases only [FeFe]-hydrogenases are found in eukaryotes, for example HYDA1 of the unicellular green alga

\footnotetext{
${ }^{a}$ Department of Physics, Experimental Molecular Biophysics, Freie Universität Berlin, Fachbereich Physik, Arnimallee 14, 14195 Berlin, Germany. E-mail: sven.stripp@fu-berlin.de; Tel: +49 3083855069

${ }^{b}$ Department of Physics, Biophysics of Metalloenzymes, Freie Universität Berlin, Arnimallee 14, 14195 Berlin, Germany. E-mail: michael.haumann@fu-berlin.de; Tel: +493083856101

${ }^{c}$ Faculty of Biology and Biotechnology, Photobiotechnology, Ruhr-Universität Bochum, 44801 Bochum, Germany. E-mail: martin.winkler-2@rub.de; Tel: +492343227049

${ }^{d}$ Faculty of Physics, St. Petersburg State University, 198504 St. Petersburg, Russian Federation

${ }^{e}$ Faculty of Chemistry and Biochemistry, Inorganic Chemistry I,

Ruhr-Universität Bochum, 44801 Bochum, Germany

$\dagger$ Electronic supplementary information (ESI) available. See DOI: 10.1039/c7cp04757f
}

Chlamydomonas reinhardtii. ${ }^{1-3}$ HYDA1 represents the 'minimal unit' of biological hydrogen conversion as it exclusively binds the catalytic cofactor. ${ }^{3}$ Prokaryotic [FeFe]-hydrogenases carry additional iron-sulfur clusters and typically stem from obligate anaerobic bacteria such as Clostridium pasteurianum (CPI) or Desulvovibrio desulfuricans (DDH). ${ }^{4-7}$ [FeFe]-hydrogenases are bidirectional enzymes that catalyze $\mathrm{H}_{2}$ oxidation and $\mathrm{H}_{2}$ release from proton reduction at negligible electrochemical overpotential. ${ }^{8-10}$ Hydrogen conversion in [FeFe]-hydrogenases was proposed to be limited by the diffusion velocity of reactants ${ }^{11-14}$ and understanding the molecular principles of hydrogen conversion in [FeFe]-hydrogenases will be an important step towards the design of bio-inspired catalysts with comparable $\mathrm{H}_{2}$ release activity. ${ }^{15-17}$

The active site cofactor of [FeFe]-hydrogenases is referred to as the $\mathrm{H}$-cluster (Fig. 1). It comprises a [4Fe-4S] cluster covalently linked to a unique diiron site with a 'proximal' and 'distal' iron ion $\left(\mathrm{Fe}_{\mathrm{p}}\right.$ and $\mathrm{Fe}_{\mathrm{d}}$, respectively). ${ }^{6} \mathrm{An}$ azadithiolate ligand (adt) bridges the two iron ions and introduces a 


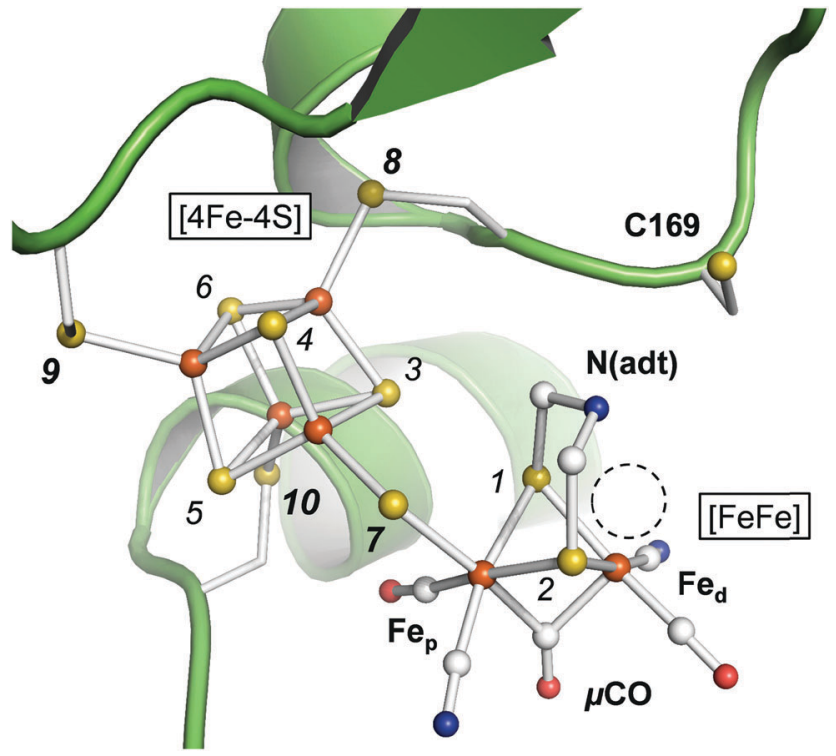

Fig. 1 Active site and catalytic cofactor in [FeFe]-hydrogenases. The crystal structure corresponds to the active-ready, oxidized state (Hox) of bacterial [FeFe]-hydrogenase CPI (PDB entry 4XDC). ${ }^{6}$ The catalytic cofactor comprises a [4Fe-4S] cluster and a diiron site, [FeFe]. $\mathrm{Fe}_{\mathrm{p}}$ and $\mathrm{Fe}_{\mathrm{d}}$ - proximal and distal iron ions. $\mu \mathrm{CO}-\mathrm{Fe}-\mathrm{Fe}$ bridging $\mathrm{CO}$ ligand. $\mathrm{N}(\mathrm{adt})$ - nitrogen headgroup of the adt ligand. The dashed circle highlights an apical vacancy at $\mathrm{Fe}_{\mathrm{d}}$. $\mathrm{C} 169$ is a conserved cysteine residue that couples the $\mathrm{H}$-cluster to the proton transfer pathway. Sulfur atoms are numbered 1-10 according to the DFT model (see the ESI $\dagger$ ).

potential nitrogen base in close proximity to $\mathrm{Fe}_{\mathrm{d}} \cdot{ }^{18-20}$ The metal ligand sphere is complemented by a terminal carbonyl (CO) and cyanide $\left(\mathrm{CN}^{-}\right)$ligand at $\mathrm{Fe}_{\mathrm{p}}$ and $\mathrm{Fe}_{\mathrm{d}}$. In the following, $\mathrm{pCO} /$ $\mathrm{CN}^{-}$and $\mathrm{dCO} / \mathrm{CN}^{-}$refer to the terminal ligands in the proximal or distal position. A third carbonyl ligand is found in the $\mathrm{Fe}-\mathrm{Fe}$ bridging position $(\mu \mathrm{CO})$, for example in the active-ready, oxidized state of the cofactor (Hox). ${ }^{21-23}$ Crystal structures have shown that $\mathrm{Fe}_{\mathrm{d}}$ exhibits a vacant, apical coordination site in Hox (Fig. 1). Binding of a fourth $\mathrm{CO}$ ligand in the CO-inhibited state $(\text { Hox-CO })^{24-27}$ has recently been proposed to result in an octahedral $\mathrm{Fe}_{\mathrm{d}}$ site with an apical $\mathrm{CN}^{-}$ligand. ${ }^{28}$ Several further redox species were identified (Table 1). Two distinct one-electron reduced states have been described, Hred and Hred', which differ in the location of the surplus electron at the $\mathrm{H}$-cluster. ${ }^{29-31}$ In the two-electron 'super-reduced' state, Hsred, $\mu \mathrm{CO}$ adopts a terminal, non-bridging position ${ }^{32}$ and a bridging hydride $(\mu \mathrm{H})$

Table 1 Electronic configuration of different redox species

\begin{tabular}{llllll}
\hline $\begin{array}{l}\text { Redox } \\
\text { species }\end{array}$ & $\Delta \mathrm{e}^{-}$ & $\begin{array}{l}{[4 \mathrm{Fe}-4 \mathrm{~S}]} \\
\text { cluster }\end{array}$ & $\begin{array}{l}\text { Diiron } \\
\text { site }^{a}\end{array}$ & $\begin{array}{l}\text { Alternative } \\
\text { annotation }\end{array}$ & Ref. \\
\hline Hox & - & +2 & I/II & - & $46-48$ \\
Hox-CO & - & +2 & I/II & - & $25-28$ \\
Hred & 1 & +1 & I/II & H'red $^{\prime}$, Hred & 29,31 and 49 \\
Hhyd & 2 & +1 & II/II & - & $37-40$ \\
Hred & 1 & +2 & I/I & HredH $^{+}$ & 21,22 and 31 \\
Hsred & 2 & +1 & I/I & - & 32 and 33
\end{tabular}

${ }^{a}$ Formal charge is given for $\mathrm{Fe}_{\mathrm{p}} / \mathrm{Fe}_{\mathrm{d}}$. Only the mixed-valence state $\mathrm{I} / \mathrm{II}$ is EPR-active. was suggested. ${ }^{33,34}$ Reorientation of $\mu \mathrm{CO}$ has been discussed also for Hred. ${ }^{22,31,33-36}$ In amino acid variants of HYDA1, another twoelectron reduced species has been observed. Hhyd carries a $\mu \mathrm{CO}$ ligand and was suggested to bind a terminal hydride in the apical position at $\mathrm{Fe}_{\mathrm{d}} \cdot{ }^{37-40}$ It needs to be clarified whether and how the various redox species are involved in the catalytic cycle. ${ }^{41-45}$

Exchange of protons between the [FeFe]-hydrogenase active site and the aqueous solvent is supported by a chain of phylogenetically conserved amino acids. In HYDA1, the putative proton transfer pathway comprises residues E144, S189, E141, C169, and at least one water molecule. ${ }^{50-52}$ Side-directed mutagenesis studies identified C169 as the primary proton relay to the diiron site of the $\mathrm{H}$-cluster ${ }^{51}$ and proton transfer is further facilitated by the N(adt) group (Fig. 1). ${ }^{18-20,35}$ Theoretical studies support a rapid exchange of protons via this 'catalytic' pathway. ${ }^{53-55}$ However, the interplay between proton transfer and electron transfer events in the hydrogen conversion reaction of [FeFe]hydrogenases remains largely unclear.

Here, we describe in situ, real-time spectroscopy on [FeFe]hydrogenase protein films under controlled variation of gas composition, sample $\mathrm{pH}$, and reductant concentration. Shifts of the $\mathrm{CO} / \mathrm{CN}^{-}$vibrational bands were used to study electron and proton transfer at the active site via attenuated total reflection Fourier-transform infrared spectroscopy (ATR FTIR). Vibrational band patterns were characterized for three different [FeFe]-hydrogenases, proteins with amino acid exchanges in the proton path, and five cofactor variants comprising alternative dithiolate groups. Redox and $\mathrm{pH}$ titrations, element and isotope exchange studies, and density functional theory (DFT) calculations identified novel $\mathrm{H}$-cluster species, most likely protonated at the $[4 \mathrm{Fe}-4 \mathrm{~S}]$ cluster.

\section{Experimental}

\section{Protein sample preparation}

[FeFe]-hydrogenase HYDA1 and CPI apo-proteins were overexpressed in Escherichia coli, purified, quantitatively reconstituted in vitro with synthetic diiron complexes $\left(\mathrm{Fe}_{2}(x)(\mathrm{CO})_{4}(\mathrm{CN})_{2}\right)$, and concentrated to $500 \mu \mathrm{M}$ protein $\left(\sim 25 \mathrm{~g} \mathrm{~L}^{-1}\right) .{ }^{20}$ The typical $\mathrm{H}_{2}$ release activity was $\sim 800 \mu \mathrm{mol} \mathrm{H}_{2} \mathrm{mg}^{-1} \mathrm{HYDA}^{\text {adt }} \min ^{-1}$ and $\sim 2500 \mu \mathrm{mol} \mathrm{H}_{2} \mathrm{mg}^{-1} \mathrm{CPI}^{\text {adt }} \mathrm{min}^{-1}$. Analyzed cofactor variants included adt $=\left(\mathrm{SCH}_{2}\right)_{2} \mathrm{NH}$, odt $=\left(\mathrm{SCH}_{2}\right)_{2} \mathrm{O}$, sdt $=\left(\mathrm{SCH}_{2}\right)_{2} \mathrm{~S}$, pdt $=\mathrm{S}_{2}\left(\mathrm{CH}_{2}\right)_{3}$, or edt $=\mathrm{S}_{2}\left(\mathrm{CH}_{2}\right)_{2}$ as bridging dithiolate groups $(x)$ at the diiron site. Site-directed mutagenesis of HYDA1 at position 169 yielded variants C169D and C169A as described earlier. ${ }^{50}$ Selenium substitution at the $[4 \mathrm{Fe}-4 \mathrm{~S}]$ cluster was performed as recently published. ${ }^{56}$ Wildtype DDH enzyme was purified from D. desulfuricans in a functional form. ${ }^{57}$ All protein preparation and handling procedures were carried out at room temperature, under strictly anoxic conditions, and dim light.

\section{Fourier-transform infrared spectroscopy}

Fig. 2 shows a schematic drawing of the experimental ATR FTIR set-up for exposure of protein films to an aerosol with defined humidity, $\mathrm{pH}$, and reactant concentration. In section (A), gasses 
(A)

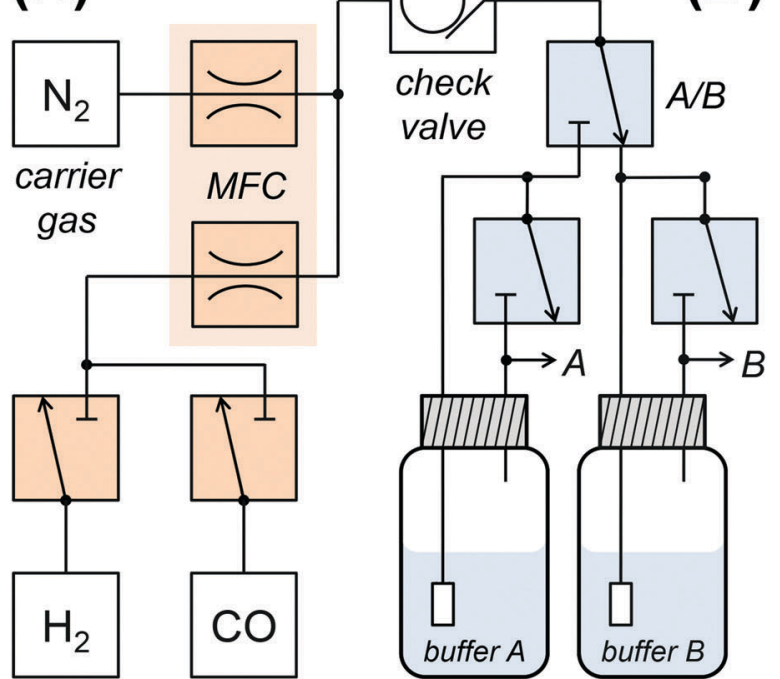

mixture of gases aerosol formation

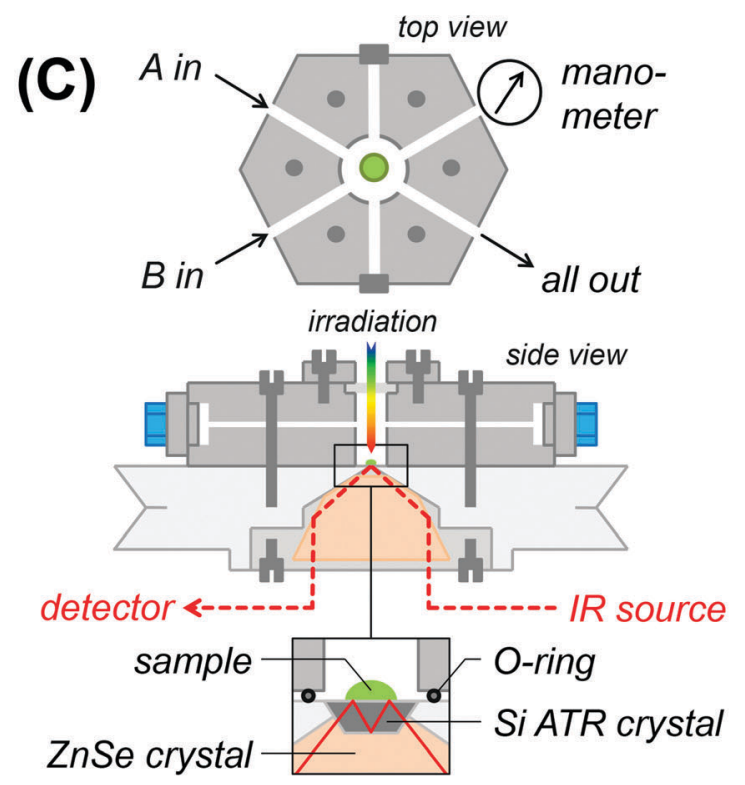

ATR FTIR spectroscopy

Fig. 2 Experimental set-up for ATR FTIR on protein films. (A) Various gases (e.g. $\mathrm{H}_{2}, \mathrm{CO}$ ) were mixed into a constant stream of $\mathrm{N}_{2}$ carrier gas. The gas flow was controlled by digital mass flow controllers (MFC). (B) Dry gas was passed through either wash bottle A or B, comprising different buffer compositions. (C) The thereby created aerosol was fed to the headspace above the protein film. On top of the ATR reflection unit, a custom-made PCTFE chamber with gas in- and outlets and manometric pressure control capped the silicon crystal and the protein film.

are mixed and the flow volume is adjusted. Dry $\mathrm{N}_{2}$ carrier gas of ultra-high purity (5.0) was provided by a nitrogen generator (PN1450, Inmatec, Germany). A constant gas stream (typically $1.5 \mathrm{~L} \mathrm{~min}^{-1}$ ) was adjusted using digital mass flow controllers (MFC, SmartTrak, Sierra, USA). Reactant gases $\left({ }^{12} \mathrm{CO},{ }^{13} \mathrm{CO}, \mathrm{H}_{2}\right.$ from Linde, Germany) were added to the $\mathrm{N}_{2}$ stream via separate flow controllers. A 200 mbar check valve separates the dry gas section (A) from the wet gas section (B). In order to create a reactive aerosol, the gas stream was passed through a wash bottle containing $150 \mathrm{~mL}$ mixed buffer (50 mM Tris, MES, PIPPS, pH 3-9) and sodium dithionite (DT) and/or methyl viologen (MV). In Fig. S1 (ESI $\dagger$ ), we demonstrate how water-soluble ingredients are transported with the aerosol stream, i.e. to reduce MV via DT enrichment. Section (C) shows the spectroscopic set-up. The aerosol was fed into a gas-tight polychlorotrifluoroethylene (PCTFE) compartment, attached on top of the ATR crystal plate and equipped with six optional gas inlets, a manometer for pressure control, and a transparent glass window for UV/vis irradiation. ${ }^{28}$ The FTIR spectrometer (Tensor27, Bruker Optik, Germany) was equipped with a triple-reflection $\mathrm{ZnSe} / \mathrm{Si}$ crystal ATR cell (Smith Detection, USA) and placed in an anaerobic chamber (Coy Laboratories, USA). Infrared spectra were recorded with $80 \mathrm{kHz}$ scanning velocity at a spectral resolution of $1 \mathrm{~cm}^{-1}$ from 3800 to $1200 \mathrm{~cm}^{-1}$. Under these conditions, the time-resolution of data acquisition is in the range of $1 \mathrm{~s}$ (one interferometer scan in the forward/backward direction). In order to determine the timescale of equilibration in the aerosol set-up, we probed a fast process, i.e. CO inhibition. ${ }^{28}$ Fig. S2 (ESI $\dagger$ ) shows the accumulation of Hox-CO upon exchange of $\mathrm{N}_{2}$ to CO gas. Here, the Hox $\rightarrow$ Hox-CO conversion rate determined by ATR FTIR largely exceeds the value suggested by flash-photolysis IR spectroscopy $\left(t_{1 / 2} \approx 3 \mathrm{~s}\right.$ and $15 \mathrm{~ms}$, respectively). ${ }^{58-60}$ The former represents the timescale of equilibration and defines the temporal resolution of the aerosol set-up. Note that all analyzed titrations proceeded by far slowly and were therefore not limited by the experimental time resolution. ATR FTIR measurements were performed at $25{ }^{\circ} \mathrm{C}$ air-conditioning and on hydrogenase films derived by controlled dehydration and rehydration of $1 \mu \mathrm{L}$ protein sample as reported earlier $(500 \mu \mathrm{M}$ hydrogenase in $100 \mathrm{mM}$ Tris/HCl pH 8, $100 \mathrm{mM} \mathrm{NaCl}$, and $2 \mathrm{mM}$ DT if not stated otherwise). Samples of anaerobically purified and activated $[\mathrm{FeFe}]$-hydrogenase typically contained the $\mathrm{H}$-cluster in a mixture of the Hox, Hox-CO, and Hred states. Hox was enriched in the film under a constant stream of $\mathrm{N}_{2}$ aerosol for 30 minutes prior to the $\mathrm{pH}$ or redox titrations.

\section{Infrared data evaluation}

A quantitative analysis of infrared spectra was performed using in-house software tools (Fig. S2, ESI $\dagger$ ). Spectra in the $1750-2150 \mathrm{~cm}^{-1}$ frequency range were corrected for background contributions (liquid $\mathrm{H}_{2} \mathrm{O}$ ) by subtraction of polynomial spline functions. The resulting spectra were normalized to unity area in the $\mathrm{CO} / \mathrm{CN}^{-}$spectral region and the $\mathrm{CO} / \mathrm{CN}^{-}$bands were fitted by Voigt functions ( $50 \%$ Gaussian and Lorentzian characters) for frequency, peak width, and relative intensity determination. A global analysis approach was used (simultaneous fitting of timeseries of spectra with a common set of frequencies and relative intensities for each $\mathrm{H}$-cluster species). The relative population of a specific $\mathrm{H}$-cluster species at a given time point was derived as the fraction of its summed $\mathrm{CO} / \mathrm{CN}^{-}$band intensities of the total (normalized) spectral intensity. We measured an experimental 
uncertainty of $<25 \%$ for the determination of rate constants in $\mathrm{pH}$ and redox titrations (Fig. S2, ESI $\dagger$ ).

\section{Density functional theory calculations}

DFT calculations on model structures of the $\mathrm{H}$-cluster were performed at the TPSSh functional and TZVP basis-set level of theory using Gaussian09. ${ }^{61-64}$ Starting models comprised the complete $\mathrm{H}$-cluster and were constructed on the basis of the crystal structure (PDB entry 4XDC) of CPI [FeFe]-hydrogenase as described previously. ${ }^{28}$ In some cases, adjacent amino acids and water molecules were included (see below). Anti-ferromagnetic coupling was assigned to the H-cluster prior to geometry optimization by proper definition of molecular fragments (broken symmetry approach). Calculations involved the COSMO solvation model $(\varepsilon=4)$. H-cluster structures with varying protonation sites were calculated. During structural relaxation, the positions of the four carbon atoms of the $\mathrm{S}^{-\mathrm{CH}_{3}}$ groups (representing the truncated terminal cysteine ligands of the H-cluster) were restraint at their crystallographic positions. ${ }^{6}$ A maximum deviation of $\sim 3 \mathrm{~cm}^{-1}$ was observed for the $\mathrm{CO}$ and $\mathrm{CN}^{-}$band frequencies between calculations on constraint or unconstraint model structures (average deviation of $\sim 1.5 \mathrm{~cm}^{-1}$ ). Vibrational frequencies for the relaxed molecular structures were derived from normal mode analysis as implemented in Gaussian09. Summed band intensities of $\mathrm{CO} / \mathrm{CN}^{-}$ligands from the calculations were normalized to unity for comparison with experimental data. For quantification of the correlation between experimental (exp) and calculated (cal) frequencies $(F)$ and relative band intensities $(I)$, the root-mean-squaredeviation (rmsd) was calculated (eqn (1), $n=$ number of $\mathrm{CO} / \mathrm{CN}^{-}$ bands). For band intensities, $\operatorname{rmsd}_{\mathrm{I}}$ values were derived using the uncorrected calculated intensities (an almost ideally linear correlation was observed for Hox: $\left.I_{\mathrm{Ox}}^{\mathrm{cal}}=0.2 \%+0.99 I_{\mathrm{Ox}}^{\mathrm{exp}}\right)$. For band frequencies, $\operatorname{rmsd}_{\mathrm{F}}$ values were calculated after correction of the calculated frequencies for a systematic deviation from ideal correlation due to the DFT theory level. ${ }^{61}$ Calculated frequencies for Hox were plotted versus the experimental Hox frequencies, a linear fit was performed yielding slope $\left(s_{\mathrm{ox}}=1.15\right)$ and offset $\left(o_{\mathrm{ox}}=\right.$ $-243 \mathrm{~cm}^{-1}$ ) values for Hox (eqn (2)). The corrected (cor) frequencies for all H-cluster species (i) were calculated using eqn (3) ( $\mathrm{n}=$ number of bands, i.e. $2 \mathrm{CN}^{-}$plus $3 \mathrm{CO}=5$ bands for, e.g., Hox) and the $s_{\text {ox }}$ and $o_{\text {ox }}$ values (meaning that $\operatorname{rmsd}_{\mathrm{F}}$ values for all species were directly comparable to the $\operatorname{rmsd}_{\mathrm{F}}$ for Hox).

$$
\begin{gathered}
\mathrm{rmsd}=\sqrt{\sum_{1-n}^{i}\left(F_{i}^{\mathrm{exp}}-F_{i}^{\mathrm{cor}}\right)^{2} / n} \\
F_{\mathrm{ox}}^{\mathrm{cal}}=o_{\mathrm{ox}}+s_{\mathrm{ox}} F_{\mathrm{ox}}^{\exp } \\
F_{i}^{\mathrm{cor}}=\left(F_{i}^{\mathrm{cal}}-o_{\mathrm{ox}}\right) / s_{\mathrm{ox}}
\end{gathered}
$$

\section{Results and discussion}

\section{IR band shifts upon acidification of [FeFe]-hydrogenase}

Fully active [FeFe]-hydrogenase HYDA1 as reconstituted with the native adt cofactor $^{19,20}$ was used to form a protein film on the ATR silicon crystal. The active-ready, oxidized state Hox was enriched to purity under a stream of humidified $\mathrm{N}_{2}$ at $\mathrm{pH} 8$ and $2 \mathrm{mM}$ sodium dithionite (DT) ${ }^{28}$ In contrast to earlier studies ${ }^{23,32}$ no build-up of reduced $\mathrm{H}$-cluster species was observed, most likely due to release of $\mathrm{H}_{2}$ from the protein film. It can be assumed that the decay rate of reduced species exceeds their formation rate and the removal of $\mathrm{H}_{2}$ via the $\mathrm{N}_{2}$ carrier gas precludes a re-reduction of enzyme. When the film was exposed to an acidified aerosol ( $\mathrm{pH} \mathrm{4,2} \mathrm{mM}$ DT), the IR band pattern of Hox was lost in favor of a novel spectrum (Fig. 3A and B). We note that the indicated $\mathrm{pH}$ values refer to the $\mathrm{pH}$ of the respective buffer used in the experiments. Based on calibration experiments, a difference of approximately $\sim 0.25 \mathrm{pH}$ units between the buffer and the sample film was estimated (Fig. S3, ESI $\dagger$ ). The novel pattern showed an up-shift of the $\mathrm{CO} / \mathrm{CN}^{-}$ bands by $4-6 \mathrm{~cm}^{-1}$ with similar relative intensities as in the Hox spectrum. Furthermore, the pattern comprised the characteristic low-frequency band of the $\mu \mathrm{CO}$ ligand, up-shifted by $10 \mathrm{~cm}^{-1}$. The conversion was found to be fully reversible when changing the $\mathrm{pH}$ in the aerosol back to alkaline values (Fig. S4 and $\mathrm{S} 5, \mathrm{ESI} \dagger)$. Although the HYDA1 $\mathrm{H}_{2}$ release activity was increasingly inhibited from $\mathrm{pH} 7$ to 5 , no structural changes were observed in the amide region when titrating the film from pH 8 to 4 (Fig. S6, ESI $\dagger$ ). Note that extreme conditions ( $\mathrm{pH} \mathrm{3,}$ $500 \mathrm{mM}$ DT) let to irreversible loss of cofactor bands (Fig. S4, ESI $\dagger$ ). Frequency shifts by $4-10 \mathrm{~cm}^{-1}$ are not compatible with redox changes at the diiron site and the shift to higher frequencies excludes a reduction of the H-cluster, e.g. by DT. Dithionite is commonly used as a reductant to promote $\mathrm{H}_{2}$ evolution from [FeFe]-hydrogenases in solution. ${ }^{65}$ Accordingly, we attribute the observed 'blue shift' to a protonation event and denote the novel species HoxH (Table 2). It is important to note that the Hox $\rightarrow$ HoxH conversion was not observed in the absence of DT (Fig. S4, ESI $\dagger$ ). This result suggests that reducing conditions are required to induce the protonation event and the shift of cofactor bands is unrelated to protonation of amino acid residues.

Exposure of bacterial [FeFe]-hydrogenases $\mathrm{CPI}^{\text {adt }}$ and native DDH to pH 4 and 2 mM DT caused a similar 'blue shift' of the Hox band pattern (Fig. 3C). Formation of HoxH was not affected by the accessory iron-sulfur clusters in the prokaryotic enzymes or amino acid differences near the H-cluster. We note that HYDA1 and CPI apo-enzymes were artificially maturated ${ }^{19,20}$ whereas DDH was isolated from $D$. desulfuricans in the native form. ${ }^{57}$ The formation of HoxH hence is unrelated to the maturation procedure. Besides HYDA $1^{\text {adt }}$, we investigated cofactor variants with a less basic (odt, sdt) or hydrophobic (pdt, edt) bridgehead group at the diiron site. For all modified enzymes, a similar Hox $\rightarrow$ HoxH conversion at pH 4 and 2 mM DT was observed (Fig. 3D). This clearly proves that the bridgehead atom does not correspond to the protonation site. However, the cofactor variant HYDA1 $^{\text {pdt }}$ showed an approximately 20 -fold slower formation of HoxH in comparison to HYDA1 ${ }^{\text {adt }}$ (Fig. S5, ESI $\dagger$ ), presumably related to the much smaller $\mathrm{H}_{2}$ release activity of the pdt variant. ${ }^{66}$ Protein variants with amino acid exchanges in the proton pathway towards the diiron site were studied (C169D and C169A). Although typical IR spectra and quantitative formation of HoxH were 

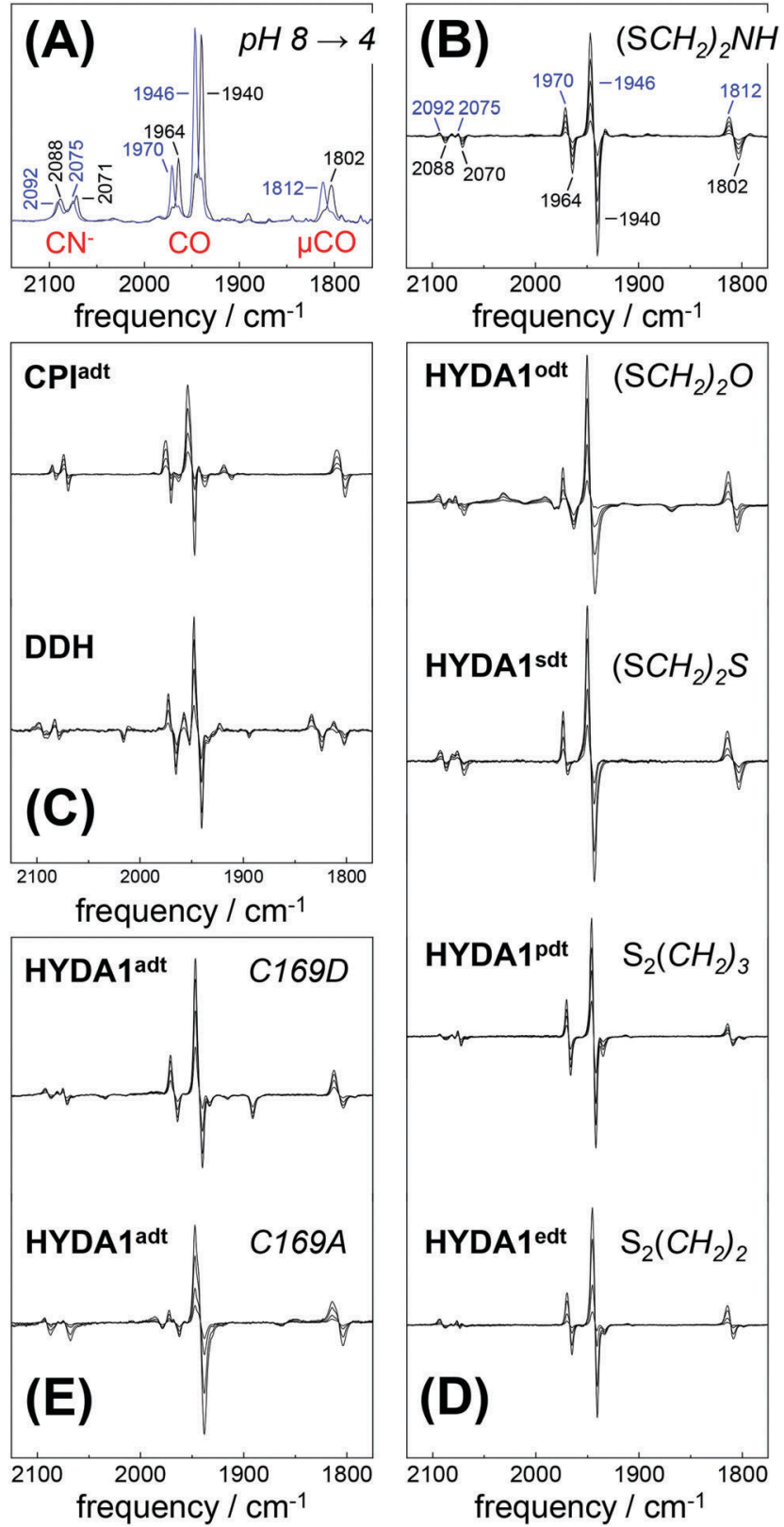

Fig. 3 FTIR difference spectra for the Hox $\rightarrow$ HoxH conversion ('blue shift'). The $\mathrm{CO} / \mathrm{CN}^{-}$spectral region is shown. (A) Absolute spectra for the Hox $\rightarrow$ HoxH conversion in native HYDA1 ${ }^{\text {adt }}$ obtained at $\mathrm{pH} 8$ (black trace) and $\mathrm{pH} 4$ in the presence of $2 \mathrm{mM} \mathrm{DT}$ (blue trace). Assignment of bands to vibrational modes was derived from DFT calculations $\left(\mathrm{CN}^{-}\right.$and $\mathrm{CO} / \mu \mathrm{CO}$ marked in red). (B) Difference spectra obtained during Hox (negative bands) to HoxH (positive bands) conversion in $\mathrm{HYDA}^{\text {adt }}$ from the same data set as in (A). (C) Difference spectra for bacterial [FeFe]-hydrogenases $\mathrm{CPI}^{\text {adt }}$ and DDH ${ }^{\text {adt }}$. (D) Difference spectra for HYDA1 cofactor variants odt, sdt, pdt, and edt. (E) Difference spectra for HYDA1 ${ }^{\text {adt }}$ amino acid variants C169A and C169D. Table S1 (ESI†) lists the vibrational frequencies for all analyzed variants.

observed in both variants (Fig. 3E), the rate of HoxH formation in the C169A variant was smaller than in wild-type HYDA $1^{\text {adt }}$ or in the C169D variant (Fig. S5, ESI $\dagger$ ), ruling out that cysteine 169 functions as the protonation site in HoxH. The amino acid variant HYDA1 C169D showed $\mathrm{H}_{2}$ release activity significantly
Table 2 IR band frequencies of $\mathrm{CO}$ and $\mathrm{CN}^{-}$ligands in $\mathrm{HYDA}^{\text {adt }}$

\begin{tabular}{|c|c|c|c|c|c|c|}
\hline \multirow{3}{*}{$\begin{array}{l}\text { H-Cluster } \\
\text { species } \\
\text { Hox }\end{array}$} & \multicolumn{5}{|c|}{ IR frequency $/ \mathrm{cm}^{-1}$} & \multirow{3}{*}{$\begin{array}{l}\begin{array}{l}\text { Additional } \\
\text { reference }\end{array} \\
21,22 \text { and } 28\end{array}$} \\
\hline & \multicolumn{2}{|c|}{$\mathrm{CN}^{-}$bands } & \multicolumn{3}{|c|}{ CO bands } & \\
\hline & 2088 & 2070 & 1964 & 1940 & 1802 & \\
\hline НохH & 2092 & 2074 & 1970 & 1946 & 1812 & This study \\
\hline Hred $^{\prime}$ & 2084 & 2066 & 1962 & 1933 & 1792 & 29,31 and 49 \\
\hline Hred $^{\prime} \mathbf{H}$ & 2086 & 2068 & 1966 & 1938 & 1800 & This study \\
\hline Hhyd & 2088 & 2076 & 1980 & 1960 & 1860 & 40 \\
\hline Hred & 2070 & 2033 & $1961^{a}$ & 1915 & 1891 & 21,22 and 31 \\
\hline Hsred & 2068 & 2026 & $1953^{a}$ & 1918 & 1882 & 32 \\
\hline Hox-CO & 2091 & 2081 & 1968 & $1962^{b}$ & 1808 & $25-28$ \\
\hline HoxH-CO & 2094 & 2086 & 1972 & $1966^{b}$ & 1816 & This study \\
\hline
\end{tabular}

${ }^{a}$ The bridging carbonyl $(\mu \mathrm{CO})$ is moved to a terminal position at $\mathrm{Fe}_{\mathrm{d}}$ in Hred and Hsred. ${ }^{b}$ In the CO-inhibited states, the coupled pCO/dCO stretching vibration gives rise to an additional IR band (Hox-CO: $2012 \mathrm{~cm}^{-1}$, HoxH-CO: $2006 \mathrm{~cm}^{-1}$ ). IR frequencies were determined from the spectra shown in Fig. 3, 6 and Fig. S7, S10 (ESI).

similar to native enzyme (up to $80 \%$ ) while HYDA1 C169A did not evolve $\mathrm{H}_{2}$ in the presence of DT and MV. We therefore assume that $\mathrm{H}_{2}$ release activity is correlated with the formation rate of HoxH.

\section{Proton and reductant concentration effects on HoxH formation}

Protein concentration, hydration level, and temperature affected the Hox $\rightarrow$ HoxH conversion rate (Fig. S6, ESI + ). Accordingly, a quantitative comparison demanded tight control of all experimental parameters. We determined an experimental uncertainty in the determination of conversion rates of less than $25 \%$ (Fig. S2, ESI $\dagger$ ) and observed negligible differences in the hydration level (Fig. S6, ESI†). Accordingly, it was possible to investigate the influence of proton and DT concentration on the yield and formation rate of HoxH. Fig. 4A shows the Hox $\rightarrow$ HoxH conversion with individual protein films after a change of the aerosol from $\mathrm{pH} 8$ to $\mathrm{pH}$ 6-4 with $10 \mathrm{mM}$ DT. To elucidate the influence of DT, HoxH formation was monitored in a concentration range of $0-1000 \mathrm{mM}$ DT at pH 6 (Fig. 4B). Aqueous solutions of DT were freshly prepared and the $\mathrm{pH}$ was checked before and after each experiment, which excluded any decomposition of DT. ${ }^{67,68}$ Clearly, the formation rate of $\mathbf{H o x H}$ depends on the DT concentration as well. The sigmoidal time course of the Hox $\rightarrow$ HoxH transition suggested that at least two consecutive processes are involved, i.e. proton transfer and electron transfer. In contrast, back conversion to Hox showed exponential behavior and the rate was found to be virtually independent of pH and DT (Fig. S5, ESI $\dagger$ ). These observations might suggest that the divergent velocity of the Hox $\leftrightarrow$ HoxH conversion is related to protein structural rearrangements in the 'blue shift' reaction. However, the formation of HoxH was not associated with changes in the protein structure or denaturation (Fig. S6, ESI $\dagger$ ). Despite the high concentrations of DT used in some experiments, no enrichment of reduced $\mathrm{H}$-cluster species was observed.

The formation rate of HoxH increased linearly with proton concentration in a $\mathrm{pH}$ range of $4-7$ at $10 \mathrm{mM}$ DT (Fig. 5A). A pH titration with a 50 -fold increase of DT (500 mM) showed an overall faster Hox $\rightarrow$ HoxH conversion and linear regression 

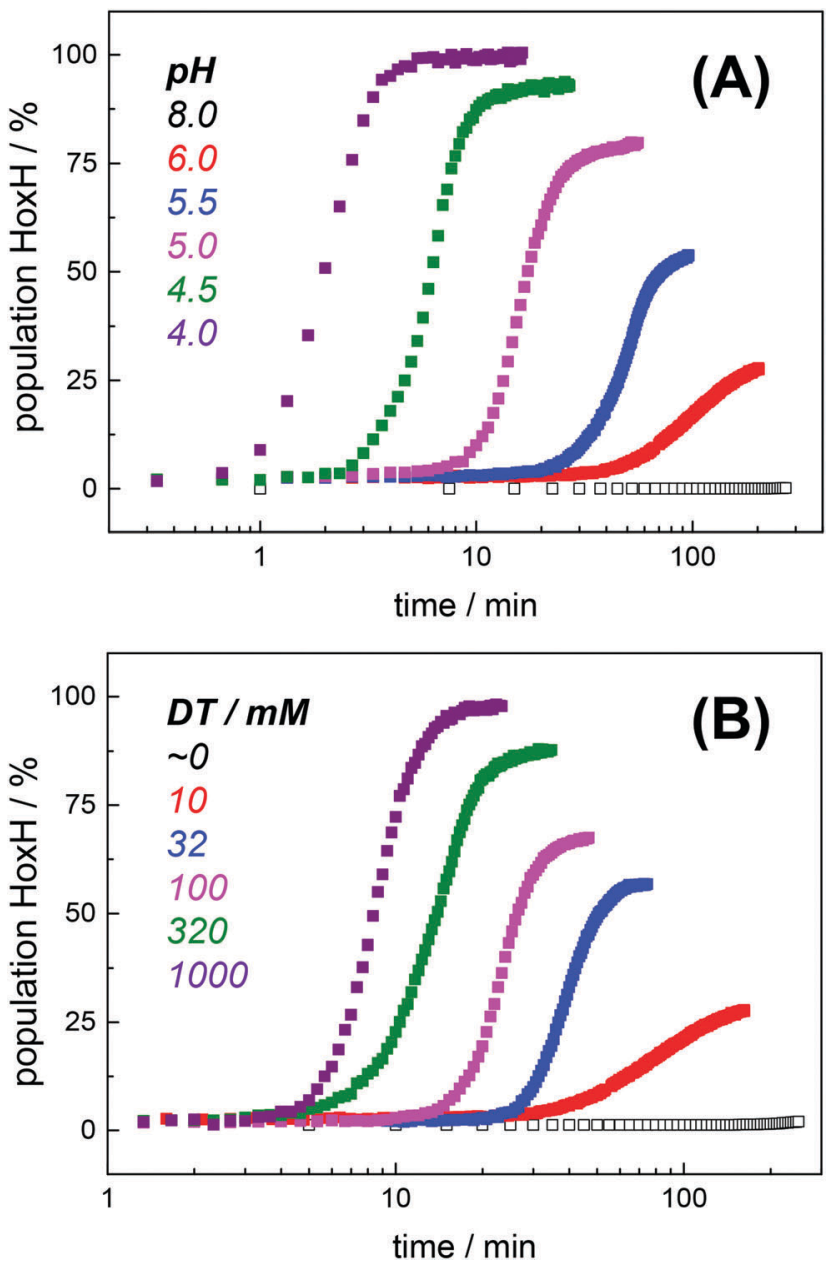

Fig. 4 Hox $\rightarrow$ HoxH conversion in HYDA1 ${ }^{\text {adt }}$ as a function of $\mathrm{pH}$ and dithionite concentration. (A) Increase of the HoxH population at a constant DT concentration of $10 \mathrm{mM}$ and pH 6-4 in the aerosol. No HoxH is observed at $\mathrm{pH} 8$ (open squares). (B) Increase of the $\mathrm{HoxH}$ population at a constant $\mathrm{pH}$ of 6 and varying DT concentration $(10-1000 \mathrm{mM})$ in the aerosol. No HoxH is observed in the absence of DT (open squares, residual DT might still be present in the preparation). Each data point in (A) and (B) corresponds to a normalized IR spectrum for which the relative HoxH population (in \%) was calculated from the respective sum of $\mathrm{CO} / \mathrm{CN}^{-}$peak areas.

from $\mathrm{pH} 3$ to 7 (Fig. S4, ESI $\dagger$ ). In contrast, saturation behavior of the HoxH formation rate was observed at excess DT concentrations (Fig. 5B). Accelerated formation of HoxH was also observed in the presence of the redox mediator MV (Fig. S5, ESI $\dagger$ ) which is often used to optimize electron transfer from DT to hydrogenase enzymes. ${ }^{65}$ Fig. 5 compares the HoxH yield for $\mathrm{pH}$ titrations at $10 \mathrm{mM}$ or $500 \mathrm{mM}$ DT, respectively. Significant formation of HoxH was observed even at alkaline $\mathrm{pH}$, and the apparent $\mathrm{p} K$ shifted from $\sim 5.5$ to $\sim 7.3$ for higher DT concentrations. The titration behavior of a protonatable group should be independent of reductant concentration. The variable, apparent $\mathrm{p} K$ value thus excludes a specific amino acid residue as the protonation site in HoxH.

\section{Ligand exchange and isotope editing at the H-cluster}

Further information on the formation of HoxH was obtained from CO-inhibition and isotopic exchange studies. HYDA $1^{\text {adt }}$
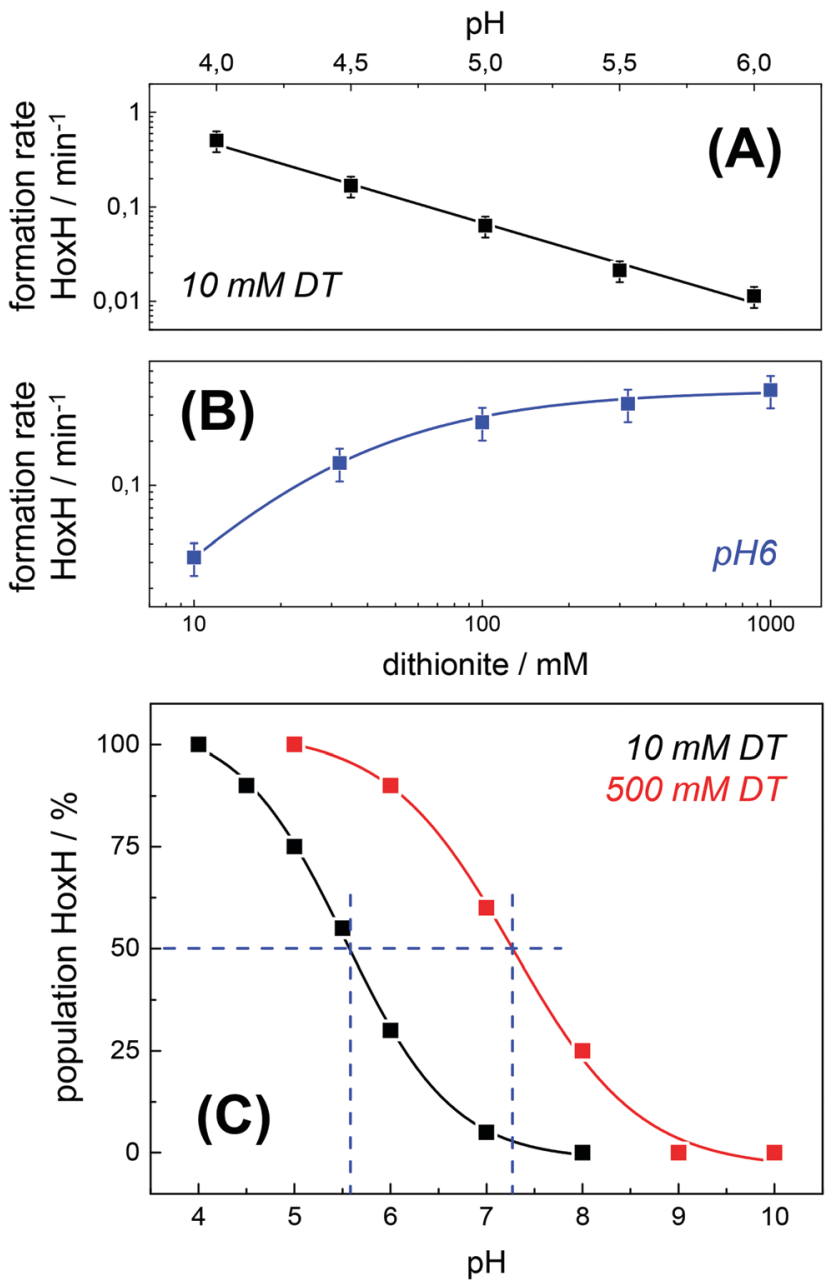

Fig. 5 Rate and yield of Hox $\rightarrow$ HoxH conversion in HYDA ${ }^{\text {adt }}$. From the time points $(t)$ of half-maximal HoxH formation, apparent rate constants $(1 / t)$ for the Hox $\rightarrow$ HoxH conversion were derived (see Fig. 4 for corresponding data). Error bars were estimated from multiple experiments under the same conditions (Fig. S2, ESI $\dagger$ ). (A) HoxH formation rate as a function of $\mathrm{pH}(10 \mathrm{mM} \mathrm{DT})$. Note the logarithmic $y$-axis, the lines show linear regressions. (B) HoxH formation rate as a function of DT concentration $(\mathrm{pH}$ 6) (the line shows a saturation curve). (C) HoxH yield as a function of $\mathrm{pH}$ for $10 \mathrm{mM}$ (black) and $500 \mathrm{mM}$ DT (red, see Fig. S4, ESI $\dagger$ for corresponding data). The apparent $\mathrm{p} K$ (blue dashes) differs by about two units.

was quantitatively inhibited with $1 \%$ CO gas, as indicated by the typical IR bands of Hox-CO (Table 2). ${ }^{28}$ Acidification in the presence of $2 \mathrm{mM}$ DT under 1\% CO induced an overall similar 'blue shift' of the $\mathrm{CO} / \mathrm{CN}^{-}$bands as observed for Hox (Fig. S7, $\mathrm{ESI} \dagger)$. We attribute the shifted spectrum to a protonated, CO-inhibited H-cluster species, HoxH-CO. Formation of HoxH-CO implies that protonation cannot occur at the distal iron ion because its ligand sphere was completed by the additional CO ligand already. ${ }^{24-28}$ Similar to the Hox $\rightarrow$ HoxH conversion, DT was required for the formation of HoxH-CO. Exchange of the bridging sulfur $(\mu \mathrm{S})$ against selenium $(\mu \mathrm{Se})$ in the $[4 \mathrm{Fe}-4 \mathrm{~S}]$ cluster of the catalytic cofactor has been shown to barely affect catalytic activity. ${ }^{56}$ Selenium-substituted HYDA1 ${ }^{\text {adt }}$ showed unchanged Hox and HoxH IR-band patterns. Although the $\mathrm{p} K$ values of thiols and selenols can differ by up to three units ${ }^{69-71}$ 
and a protonation event at $\mu \mathrm{Se}$ of the $[4 \mathrm{Fe}-4 \mathrm{Se}]$ cluster should influence the formation rate of $\mathbf{H o x H}$, the latter was not found to be affected (Fig. S8, ESI $\dagger$ ). Therefore, direct protonation of the bridging sulfur atoms in the $[4 \mathrm{Fe}-4 \mathrm{~S}]$ cluster seems to be less likely. Exposure of [FeFe]-hydrogenase to an aerosol containing $\mathrm{D}_{2} \mathrm{O}$ instead of $\mathrm{H}_{2} \mathrm{O}$ facilitated quantitative deuteration of the protein film (Fig. S9, ESI $\dagger$ ). For diiron model complexes, protonation at the bridging thiolate sulfur atoms has been considered. $^{72-74}$ The frequency down-shift of the S-H vibration upon deuteration ${ }^{75}$ from $\sim 2550$ to $\sim 1850 \mathrm{~cm}^{-1}$ could help in identifying protonation of the dithiolate ligand at the diiron site due to vibrational coupling with the $\mathrm{CO} / \mathrm{CN}^{-}$ligands. However, formation of $\mathbf{H o x H}$ in the presence of $0.5 \% \mathrm{D}_{2} \mathrm{SO}_{4}$ and $2 \mathrm{mM}$ DT did not result in altered Hox and HoxH IR-band patterns (Fig. S9, ESI $\dagger$ ), even when HYDA1 was isolated and activated in the presence of $\mathrm{D}_{2} \mathrm{O}$ before film formation and acidification. A direct detection of SH/SD bands in the sample is unrelated to vibrational coupling with the cofactor ligands and was not attempted. These results render protonation of the thiolate sulfur atoms at the diiron site in HoxH less likely.

\section{Reduction of HYDA1 with $\mathrm{H}_{2}$}

The $\mathrm{H}_{2}$ uptake activity of HYDA1 ${ }^{\text {adt }}$ was exploited to enrich reduced $\mathrm{H}$-cluster species in the protein film. In the presence of $10 \% \mathrm{H}_{2}$ the IR signature of Hox was lost in favor of band patterns mainly attributable to reduced species (Fig. 6 and Table 2). In the $\mathrm{H}_{2}-\mathrm{N}_{2}$ difference spectrum at $\mathrm{pH}$ 8, prominent CO bands at $1933 \mathrm{~cm}^{-1}$ and $1792 \mathrm{~cm}^{-1}$ resembled a pattern previously observed in reduced HYDA1 ${ }^{\text {pdt }}$ enzyme. ${ }^{29}$ These bands have been assigned to Hred' ${ }^{\prime}$ in HYDA1 ${ }^{\text {adt }}$ recently. ${ }^{31,49}$ Interestingly, we found that Hred' was favored over Hred when progressing from acidic to alkaline $\mathrm{pH}$, and vice versa (Fig. S10, ESI $\dagger$ ). This can be explained by the PCET reactivity in the formation of Hred and destabilization of the reduced diiron site at alkaline $\mathrm{pH}^{31}{ }^{31}$ For a distinct assignment of IR band patterns, we exchanged the bridging and distal ${ }^{12} \mathrm{CO}$ ligands in HYDA $1{ }^{\text {adt }}$ to ${ }^{13} \mathrm{CO}$, following a previously established protocol. ${ }^{28}$ Reduction of the isotope-edited enzyme with $\mathrm{H}_{2}$ facilitated direct assignment of the bands at $1891 \mathrm{~cm}^{-1}$ and $1933 \mathrm{~cm}^{-1}$ to dCO of Hred and Hred', respectively (Fig. 6). Whether the $\mu \mathrm{CO}$ band at $1792 \mathrm{~cm}^{-1}$ belonged to Hred or Hred' still remains unclear. To refine the assignment, $\mathrm{HYDA}^{\text {adt }}$ was reduced under $10 \% \mathrm{H}_{2}$ and titrated from $\mathrm{pH} 8$ to $\mathrm{pH} 6$ (Fig. 6 and Fig. S10, ESI $\dagger$ ). Although the $\mathrm{H}_{2}$ concentration was kept constant, acidification caused pronounced changes in the relative population of redox species and Hsred and Hred' were lost in favor of Hred and Hox. Due to the concomitant decrease of bands at $1933 \mathrm{~cm}^{-1}$ (dCO) and $1793 \mathrm{~cm}^{-1}(\mu \mathrm{CO})$, the experiment facilitated a clear assignment of these bands to Hred $^{\prime}$ (Table 2). The deviating pH-dependence of bands at $1933 \mathrm{~cm}^{-1}$ and $1891 \mathrm{~cm}^{-1}$ further distinguishes Hred' from Hred (Fig. S10, ESI $\dagger$ ). In agreement with former observations, ${ }^{40}$ an increase of Hhyd was observed when decreasing the $\mathrm{pH}$ from 8 to 6 (Fig. 6). We observed no 'blue shift' of the marker bands of Hred $\left(1891 \mathrm{~cm}^{-1}\right)$ and Hsred $\left(1882 \mathrm{~cm}^{-1}\right)$ at acidic $\mathrm{pH}$.

To investigate Hred' in greater detail, we focused on HYDA1 cofactor variant pdt. This variant does not form Hred and
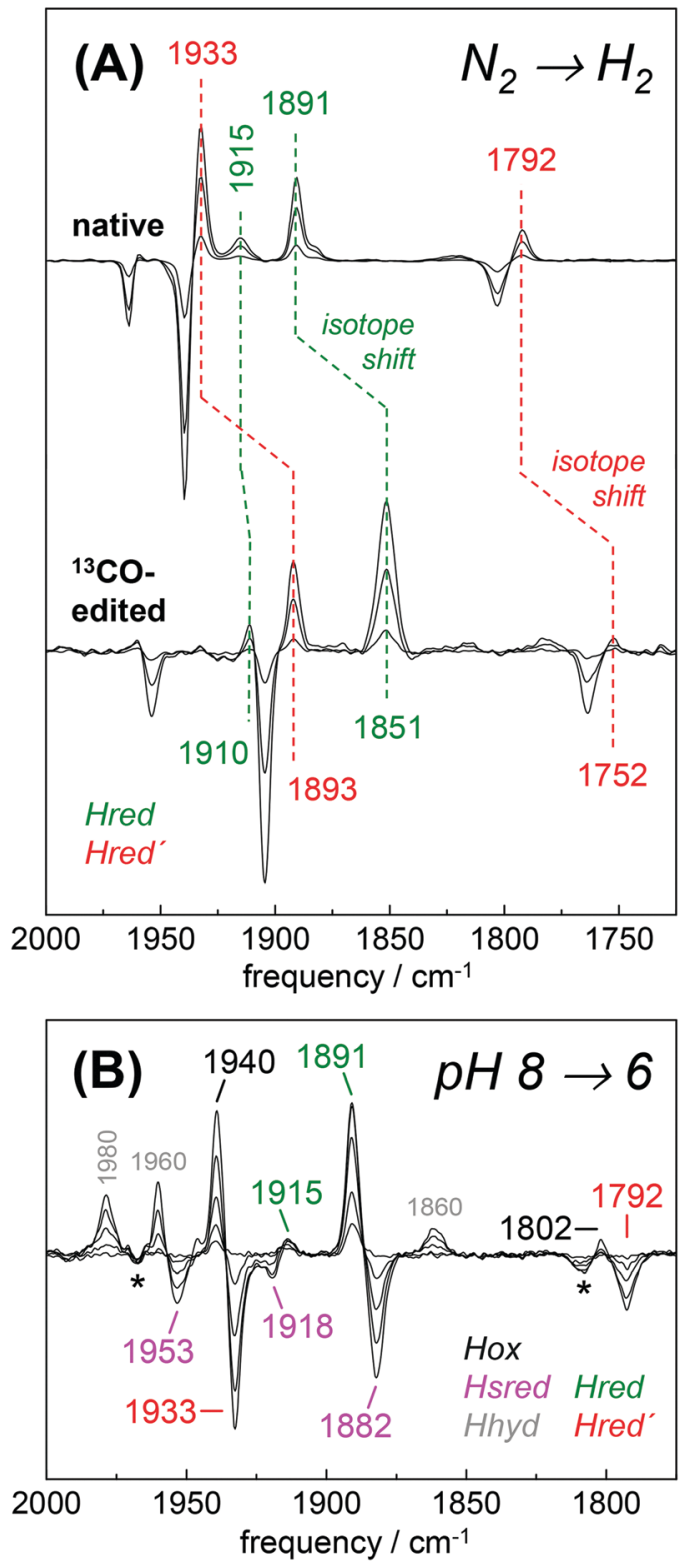

Fig. 6 Reduction of HYDA1 ${ }^{\text {adt }}$ in the presence of $H_{2}$. (A) IR difference spectra in the $\mathrm{CO}$ region collected during a change from $100 \% \mathrm{~N}_{2}$ to $10 \% \mathrm{H}_{2}$ on native (top) and ${ }^{13} \mathrm{CO}$-edited HYDA1 ${ }^{\text {adt }}$ (bottom). Spectra show an increase of Hred (green) and Hred' (red) at the expense of Hox (black). Isotope editing of the $\mu \mathrm{CO}$ and $\mathrm{dCO}$ ligands leads to $\sim 40 \mathrm{~cm}^{-1}$ frequency down-shifts in Hox, Hred, and Hred'. (B) Difference spectra for changing the $\mathrm{pH}$ from 8 to 6 in the presence of $10 \% \mathrm{H}_{2}$ (for absolute spectra see Fig. S10, ESI†). Here, Hred (green) and Hox (black) are populated at the expense of Hred' (red) and Hsred (magenta). Note the additional formation of Hhyd (grey) and decrease of the minor Hox-CO population (asterisks).

Hsred and therefore represents an excellent model to study the relation between Hox and Hred' ${ }^{29}$ Although HYDA1 ${ }^{\text {pdt }}$ has been reported to show only minimal $\mathrm{H}_{2}$ uptake activity, ${ }^{66}$ we observed quantitative Hox $\rightarrow$ Hred $^{\prime}$ conversion under $100 \% \mathrm{H}_{2}$ (Fig. 7). At pH 8, both states showed similar IR band patterns as in HYDA1 ${ }^{\text {adt }}$ with relative frequency shifts of less than $5 \mathrm{~cm}^{-1}$. When HYDA1 ${ }^{\text {pdt }}$ was purged with $\mathrm{N}_{2}$ at $\mathrm{pH} 4$ and in the presence of $2 \mathrm{mM}$ DT, an IR spectrum similar to the one of 

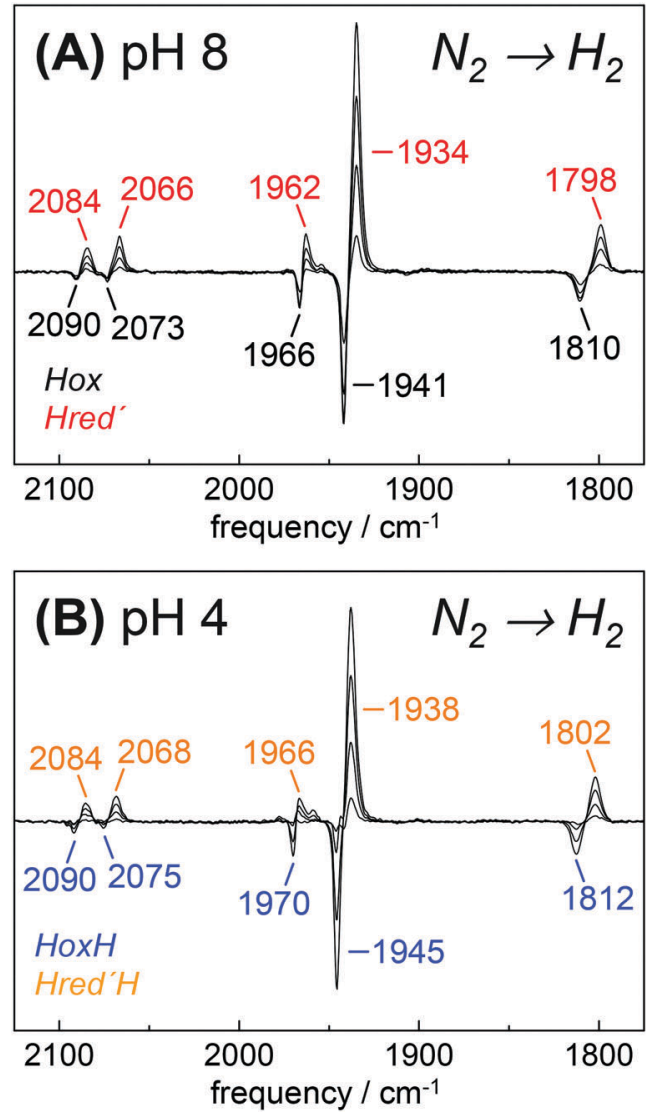

Fig. 7 Reduction of HYDA1 ${ }^{\text {pdt }}$ in the presence of $\mathrm{H}_{2}$. IR difference spectra collected during a change in the aerosol from $\mathrm{N}_{2}$ to $\mathrm{H}_{2}$. (A) At $\mathrm{pH} 8$ and 2 mM DT, Hox (black) was found to be de-populated in favor of Hred' (red). (B) At pH 4 and 2 mM DT, HoxH (blue) converted into Hred'H (orange).

HoxH was observed (compare Fig. 3). Exposure to $100 \% \mathrm{H}_{2}$ under acidic conditions resulted in a minor 'blue shift' of all $\mathrm{CO} / \mathrm{CN}^{-}$bands with respect to Hred' (Fig. 7). We denote the species responsible for this shifted spectrum as $\mathbf{H r e d}^{\prime} \mathbf{H}$ (Table 2). Redox titrations indicated the presence of $\mathbf{H r e d}^{\prime} \mathbf{H}$ in HYDA $1^{\text {adt }}$ as well, although this state was more difficult to detect in native enzyme due to competing population of Hred/ Hsred and Hhyd (Fig. S10, ESI $\dagger$ ). ${ }^{40}$

When the hydrogenase concentration in the film was decreased by dilution with bovine serum albumin protein (BSA), the Hox $\rightarrow$ Hred $^{\prime}$ conversion rate drastically dropped for relative concentrations of $\mathrm{HYDA} 1^{\mathrm{pdt}}$ below $25 \%$ and no formation of reduced states was observed with 5\% HYDA1 (Fig. S11, ESI $\dagger$ ). This behavior suggests that the inter-molecular electron transfer between [FeFe]-hydrogenase molecules (disproportionation) was involved in the formation of one-electron reduced Hred ${ }^{\prime}$ from oxidized Hox via two-electron reduced species transiently formed upon reduction with $\mathrm{H}_{2}$. Inefficient inter-molecular electron transfer may explain the low rates of $\mathrm{H}_{2}$ uptake that have been reported for HYDA ${ }^{\text {pdt }}$ in solution. ${ }^{66}$ In contrast, the formation rate of HoxH was only slightly affected by dilution of HYDA $^{\text {pdt }}$ with BSA (Fig. S11, ESI $\dagger$ ). This observation rules out inter-molecular electron transfer as an explanation for the apparent absence of reduced species in the presence of high DT concentrations.

\section{Density functional theory on $\mathrm{H}$-cluster protonation}

DFT calculations on H-cluster model structures (Fig. S12, ESI $\dagger$ ) were used to explore conceivable protonation sites. Respective positions included $\mathrm{N}(\mathrm{adt})$, the $\mu \mathrm{S}$ atoms in the diiron site $(\mathrm{S} 1, \mathrm{~S} 2)$ and in the $[4 \mathrm{Fe}-4 \mathrm{~S}]$ cluster (S3-S6), as well as the sulfur atoms of the three terminal cysteine ligands (S8-S10). Good agreement between the experimental and calculated $\mathrm{CO} / \mathrm{CN}^{-}$ band patterns of Hox was obtained, as judged on the basis of the small root-mean-square-deviations (rmsd) derived from experimental and calculated band frequencies $(F)$ and intensities (I), i.e. $\operatorname{rmsd}_{\mathrm{F}} \sim 8 \mathrm{~cm}^{-1}$ and $\mathrm{rmsd}_{\mathrm{I}}<3 \%$ (Fig. 8). ${ }^{28}$ We note that relative band positions and intensities of all investigated H-cluster species were largely independent of the size of the model structure and geometry-optimization restraints that were
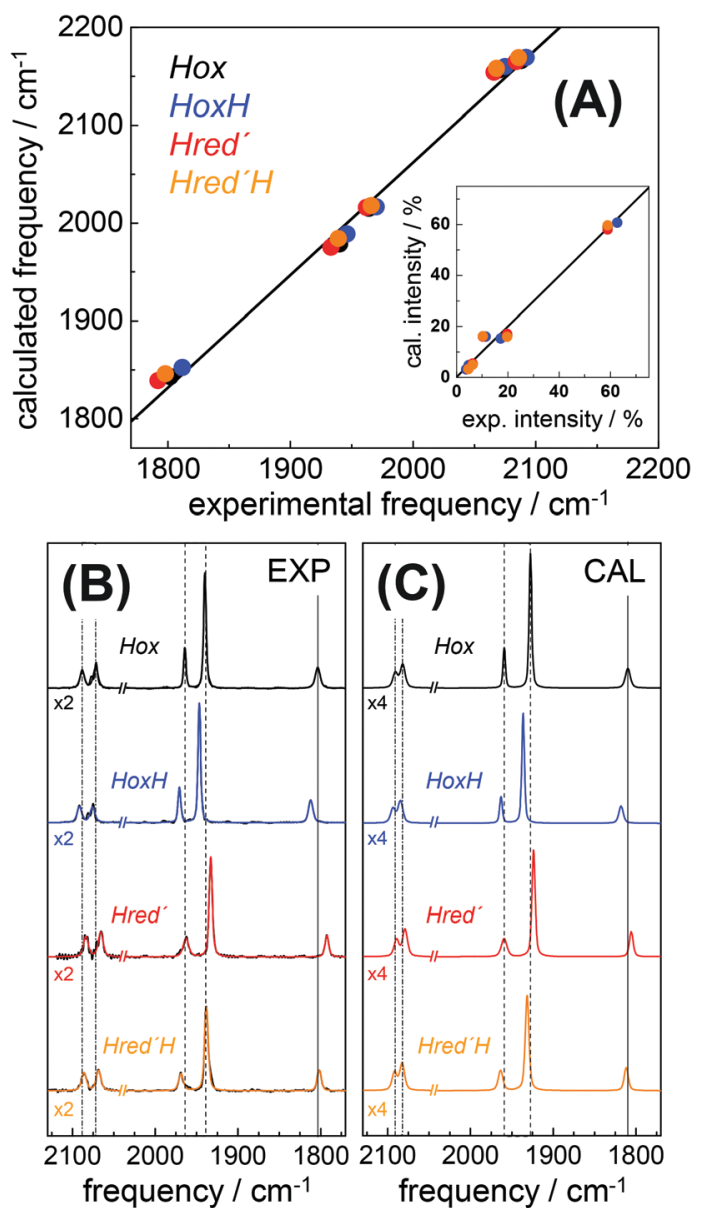

Fig. 8 Comparison of IR spectra from experiment and theory. (A) Plots of calculated (cal) vs. experimental (exp) IR frequencies and intensities (inset) for Hox, HoxH, Hred', and Hred'H. (B) Experimental normalized IR spectra (black thin lines) and fit curves (smooth lines). (C) Calculated normalized IR spectra (from DFT at the TPSSh/TZVP level and after correction of band frequencies for systematic effects, eqn (1)-(3)). Dashed lines in (B) and (C) emphasize band shifts relative to Hox; $\mathrm{CN}^{-}$bands were scaled by factors of 2 (exp) or 4 (cal) for clarity. Experimental and calculated IR data of Hox-CO and HoxH-CO are shown in Fig. S15 (ESI†). 
used in the calculations (Fig. S13, ESI $\dagger$ ). Protonation at N(adt) or $\mathrm{S} 1 / \mathrm{S} 2$ at the diiron site caused frequency up-shifts three to four fold larger than experimentally observed for HoxH (compare Table 1). The large $\operatorname{rmsd}_{\mathrm{F}}$ values $\left(15-25 \mathrm{~cm}^{-1}\right)$ suggested that these groups are unlikely protonation sites (Fig. S14, ESI $\dagger$ ). Protonation at the $\mu \mathrm{S}$ atoms of the $[4 \mathrm{Fe}-4 \mathrm{~S}]$ cluster caused band shifts in better agreement with the experiment $\left(\operatorname{rmsd}_{\mathrm{F}} 8-11 \mathrm{~cm}^{-1}\right)$. However, protonation of S3 or S5 produced a downshift of the pCO band and intensity changes less compatible with the experimental observations. Furthermore, protonation at S4 or S6 caused considerable distortion of the $[4 \mathrm{Fe}-4 \mathrm{~S}]$ cluster $($ e.g. $>0.5$ A elongation of the $\mathrm{S} 4 / \mathrm{S} 6-\mathrm{Fe}$ bonds), which rendered $\mu \mathrm{S}$ atom protonation at the $[4 \mathrm{Fe}-4 \mathrm{~S}]$ cluster less likely. This interpretation is in line with previous theoretical results on $[4 \mathrm{Fe}-4 \mathrm{~S}]$ clusters. $^{76}$ Protonation at S10 of a terminal cysteine ligand yielded a frequency downshift of the pCO band not observed in the experiment. In contrast, good agreement was found for protonation at S8 or S9 $\left(\operatorname{rmsd}_{\mathrm{F}} \sim 7 \mathrm{~cm}^{-1}\right)$. Best overall agreement with the HoxH band pattern was observed for protonation at S9 (Fig. 8). Protonation at water molecules in the vicinity of the [4Fe-4S] cluster or at the bridging cysteine $\mathrm{S} 7$ caused significantly larger IR band shifts than protonation at S9 (Fig. S14, ESI $\dagger$ ). Notably, deuteration at $\mathrm{S} 9$ caused negligible $\mathrm{CO} / \mathrm{CN}^{-}$band shifts $\left(<1 \mathrm{~cm}^{-1}\right)$, in good agreement with the experimental data of HoxH in $\mathrm{D}_{2} \mathrm{O}$ buffer and HoxH-CO (Fig. S14 and S15, ESI $\dagger$ ).

Infrared spectra were calculated for H-cluster structures of the one-electron reduced Hred' state. A Hox-like structure with a $\mu \mathrm{CO}$ ligand and apical vacancy at the distal iron ion yielded a mean frequency down-shift of $\sim 35 \mathrm{~cm}^{-1}$ of the $\mathrm{CO} / \mathrm{CN}^{-}$bands, far larger than experimentally observed (Fig. S16, ESI $\dagger$ ). Excess frequency down-shifts $\left(\mathrm{rmsd}_{\mathrm{F}}>30 \mathrm{~cm}^{-1}\right)$ were also observed for protonation of the reduced H-cluster at N(adt) or S1/S2. Inclusion of an apical hydride at the distal iron ion produced excess frequency up-shifts $\left(\operatorname{rmsd}_{\mathrm{F}} \sim 40 \mathrm{~cm}^{-1}\right)$, in particular for the $\mu \mathrm{CO}$ ligand, resembling the $\mu \mathrm{CO}$ shift in Hhyd. ${ }^{37-40}$ Protonation at one of the sulfur atoms of the $[4 \mathrm{Fe}-4 \mathrm{~S}]$ cluster yielded small IR band down-shifts in good agreement with the experiment, but led to structural distortions, whereas protonation at a cysteine sulfur preserved the cubane geometry in Hred'. Best agreement between calculated and experimental IR frequencies of Hred' was obtained for protonation at S9 $\left(\operatorname{rmsd}_{\mathrm{F}} \sim 9 \mathrm{~cm}^{-1}\right.$, see Fig. 8). These results showed that the IR spectrum of Hred' is well compatible with a one-electron reduced $\mathrm{H}$-cluster, which carries an additional proton and adopts a similar geometry to Hox. Structures for $\mathbf{H r e d}^{\prime} \mathbf{H}$ were calculated comprising a secondsite protonation. Similar trends with respect to structural changes and IR patterns in response to protonation at various sites as for HoxH and Hred' were observed (Fig. S16, ESI $\dagger$ ). Protonation at two cysteine $\mathrm{S}$-atoms of the $[4 \mathrm{Fe}-4 \mathrm{~S}]$ cluster (i.e., S8 and S9) yielded IR frequencies in good agreement with the $\mathbf{H r e d}^{\prime} \mathbf{H}$ spectrum (Fig. 8). Accordingly, Hred'H was attributed to a double-protonated H-cluster species with the same electron count and cofactor geometry as Hred'.

Good agreement between calculated and experimental IR band patterns for Hox/HoxH, and $\mathbf{H r e d}^{\prime} / \mathbf{H r e d}^{\prime} \mathbf{H}$ facilitated assignment of the IR bands of the $\mathrm{CO} / \mathrm{CN}^{-}$ligands to individual vibrational modes. In addition, our simulations provided access to the spin and charge distribution of the cofactor (Fig. S17, ESI $\dagger$ ). Protonation (i.e. at S9) and protonation/reduction affected the largely uncoupled behavior of the diatomic ligand vibrations only marginally. In the four states, the spin density distribution at the diiron site was similar, showing that the apparent mixedvalence $\mathrm{Fe}(\mathrm{I}) \mathrm{Fe}(\mathrm{II})$ configuration was preserved. The net spin thus resided largely on the diiron site in Hox/HoxH, in agreement with EPR data. ${ }^{46-48}$ For $\mathbf{H r e d}^{\prime} / \mathbf{H r e d}^{\prime} \mathbf{H}$, the spin density implied that the surplus electron was localized mainly at the $[4 \mathrm{Fe}-4 \mathrm{~S}]$ cluster, as supported by the increased negative charge density on the $[4 \mathrm{Fe}-4 \mathrm{~S}]$ cluster. Anti-ferromagnetic coupling between the unpaired spins at the diiron site and at the reduced $[4 \mathrm{Fe}-4 \mathrm{~S}]$ cluster was expected to render these states EPR-silent. ${ }^{29}$ The minor charge variations at the iron ions of the diiron site correlate well with the small experimental IR band frequency differences of the CO ligands in the four states (Fig. S17, ESI $\dagger$ ).

\section{Protonation at the H-cluster}

Real-time ATR FTIR spectroscopy on [FeFe]-hydrogenase protein films identified four states of the H-cluster that show similar $\mathrm{CO} /$ $\mathrm{CN}^{-}$band patterns but differ in the redox and/or protonation state (Hox/HoxH and $\left.\mathbf{H r e d}^{\prime} / \mathbf{H r e d}^{\prime} \mathbf{H}\right)$. The oxidized state, Hox, has been characterized extensively. In agreement with crystallographic assignments $^{4-7}$ and previous FTIR studies, ${ }^{21-28}$ DFT favored a $\mu \mathrm{CO}$ ligand and an apical vacancy at the distal iron ion in Hox. ${ }^{77}$ Our calculations suggest similar cofactor structures in all four species. Furthermore, both Hox and HoxH can be assigned to a mix-valence diiron site with an oxidized [4Fe-4S] cluster $^{46-48}$ while in Hred $^{\prime}$ and $\mathbf{H r e d}^{\prime} \mathbf{H}$ a reduced [4Fe-4S] cluster was identified. ${ }^{29}$ The mixed-valence state clearly distinguishes

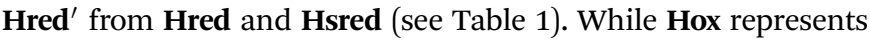
the unprotonated $\mathrm{H}$-cluster, protonation at the diiron site has been suggested for Hred and Hsred..$^{31-34,38}$ We found that a satisfactory calculation of the Hred' band pattern also requires addition of a proton. This view is supported by the experimentally observed pH-dependence of Hred $^{\prime}$ formation in both HYDA1 ${ }^{\text {pdt }}$ and HYDA1 ${ }^{\text {adt }}$. However, protonation of the diiron site or at surrounding amino acid residues cannot explain the observed IR band shifts. Our computational results favor a terminal cysteine ligand of the $[4 \mathrm{Fe}-4 \mathrm{~S}]$ cluster as a common protonation site in HoxH and Hred'/Hred 'H. In HYDA1, cysteine 417 (S9) is the most likely candidate. Additional protonation occurs in $\operatorname{Hred}^{\prime} \mathbf{H}$, presumably at C170 (S8). Iron-sulfur clusters are typically involved in electron transfer processes, but their participation in proton transfer has been documented as well. ${ }^{78-82}$ More specifically, protonation at a terminal cysteine ligand has been proposed to be involved in the catalytic mechanism of [NiFe]-hydrogenases. ${ }^{83-86}$

Formation of HoxH and $\mathbf{H r e d}^{\prime} / \mathbf{H r e d}^{\prime} \mathbf{H}$ was found to be independent of the proton pathway to the active site that includes C169, N(adt), and $\mathrm{Fe}_{\mathrm{d}}$. The crystal structure of the HYDA1 apoprotein $^{87}$ suggests that the $[4 \mathrm{Fe}-4 \mathrm{~S}]$ cluster in HYDA1 is in direct contact with bulk water while in bacterial [FeFe]-hydrogenases, the H-cluster is buried deeper in the catalytic domain. ${ }^{4-7}$ However, a chain of water molecules extends from the surface close to the cysteine that corresponds to our favored protonation site at the 
[4Fe-4S] cluster (Fig. S18, ESI $\dagger$ ). Two proton trajectories thus may be present in [FeFe]-hydrogenases: the 'catalytic' proton pathway that shuttles protons to the diiron site ${ }^{50-52}$ and a pathway that facilitates protonation at the $[4 \mathrm{Fe}-4 \mathrm{~S}]$ cluster.

\section{Reaction sequence of electron and proton transfer}

While the exponential HoxH $\rightarrow$ Hox conversion implies a direct deprotonation of the $[4 \mathrm{Fe}-4 \mathrm{~S}]$ cluster, the sigmoidal time course of HoxH formation suggests at least two successive reaction steps to be involved in the 'blue shift' reaction. HoxH was found to accumulate under $\mathrm{H}_{2}$ release conditions, that is, for increasing concentrations of the reductant (such as the oneelectron donor sodium dithionite, DT). This places HoxH towards the end of a multi-step reaction cycle (Fig. S19, ESI $\dagger$ ). Under conditions of maximal $\mathrm{H}_{2}$ release (e.g. $\mathrm{pH} 7-8,200 \mathrm{mM}$ DT as in Fig. S6, ESI $\dagger$ ) the prevalence of Hred' over Hred suggests Hred' as an intermediate in the Hox $\rightarrow$ HoxH conversion. Hox dominates at alkaline $\mathrm{pH}$ so that we assume that deprotonation of HoxH is required to regain Hox. In contrast, the quantitative accumulation of HoxH suggests that this deprotonation was slow or impaired at low pH. Numerical simulations show that the above considerations can qualitatively reproduce the $\mathrm{pH}$ and DT dependence of HoxH formation (Fig. S20, ESI $\dagger$ ). This model also consistently explains the formation of HoxH-CO due to reductive conversion of Hox-CO into Hred' $^{\prime}, \mathrm{H}_{2}$ release, and subsequent rebinding of $\mathrm{CO}$ to HoxH (Fig. S7, ESI $\dagger$ ). It has been shown that reduction of the $[4 \mathrm{Fe}-4 \mathrm{~S}]$ cluster weakens the binding of external CO. ${ }^{13,29}$

Our data provide evidence that protonation at the same cysteine ligand of the $[4 \mathrm{Fe}-4 \mathrm{~S}]$ cluster occurred in both $\mathbf{H o x H}$ and Hred'. We assume that this protonation occurs from a putative donor group $\left(\mathrm{BH}^{+}\right)$, such as a water molecule consistently observed in CPI and DDH structures (Fig. S18, ESI $\dagger$ ). ${ }^{4-7}$ Deprotonation of HoxH likely involves the same molecule, now serving as a proton acceptor (B). Re-protonation of this group at acidic $\mathrm{pH}$ (i.e. via the adjacent chain of water molecules) would impair the deprotonation reaction so that HoxH accumulates (Fig. S19, ESI $\dagger$ ). Hred $^{\prime} \mathbf{H}$ is populated upon reduction and protonation of HoxH at low $\mathrm{pH}$, but seems not to advance further in the reaction cycle, possibly because second-site protonation interferes with the $\mathrm{H}_{2}$ forming reactions. Further studies are required to clarify this point. Accumulation of Hred' ${ }^{\prime}$ under $\mathrm{H}_{2}$ likely involves inter-molecular electron transfer between oxidized and (transiently formed) two-electron reduced [FeFe]-hydrogenase proteins (either in the Hsred or Hhyd states). We note that inter-molecular electron transfer seems to require a densely packed protein film and is unlikely to occur under physiological conditions.

\section{Conclusions}

In contrast to Hox and Hred', Hred and Hsred carry an additional electron at the diiron site and lack the $\mathrm{Fe}-\mathrm{Fe}$ bridging $\mathrm{CO}$ ligand. ${ }^{31-34,38}$ Respective ligand rotation into a terminal or "semi-bridging" position has been considered difficult to reconcile with the large hydrogen turnover rates of [FeFe]-hydrogenases. ${ }^{41-43}$
An involvement of Hred and Hsred in hydrogen turnover is certainly not excluded at present. ${ }^{31,38,60}$ However based on the differences in ligand orientation (bridging $v s$. terminal), these states can be considered unlikely intermediates in the reaction cycle of rapid $\mathrm{H}_{2}$ formation. ${ }^{34}$ In $\mathrm{HYDA}{ }^{\text {adt }}$, formation of Hred was suppressed at alkaline $\mathrm{pH}$ in favor of Hred $^{\prime}$ while for acidic $\mathrm{pH}$ values Hred dominated over Hred'. Thus, the relative population of Hred and Hred' in HYDA $1^{\text {adt }}$ critically depends on $\mathrm{pH}$. This suggests that the rates of proton delivery either to the $[4 \mathrm{Fe}-4 \mathrm{~S}]$ cluster or to the diiron site may be decisive for the location of electrons at the H-cluster. In addition to the 'catalytic' proton pathway towards the diiron site,$^{50-55}$ we propose a 'regulatory' proton pathway to the $[4 \mathrm{Fe}-4 \mathrm{~S}]$ cluster. Concomitant protonation and reduction at the $[4 \mathrm{Fe}-4 \mathrm{~S}]$ cluster in Hred $^{\prime}$ stabilize the mixed-valence state and prevent ligand rotation and premature protonation at the diiron site. Whether this is a sequential or concerted process remains to be elucidated. ${ }^{88-90}$

\section{Conflicts of interest}

There are no conflicts to declare.

\section{Acknowledgements}

The authors thank J. Fontecilla-Camps (Institut de Biologie Structurale, Grenoble) for generously providing a sample of DDH protein and P. Chernev (Freie Universität Berlin) for kindly providing data analysis software. M. S. and S. T. S. thank the International Max Planck Research School (IMPRS) on Multiscale Biosystems and the Focus Area NanoScale (Freie Universität Berlin) for financial support. M. H. gratefully acknowledges funding by the Bundesministerium für Bildung und Forschung (Grant 05K14KE1). M. W. and T. H. thank the Volkswagen Foundation for funding (Grant LigH2t) and the Deutsche Forschungsgemeinschaft (DFG) for support within the Cluster of Excellence RESOLV (EXC 1069). U.-P. A. gratefully acknowledges financial support by the Fonds der Chemischen Industrie (Liebig Grant) and the DFG (Emmy Noether Grant AP242/2-1). J. D. thanks the China Scholarship Council (CSC) for support and L. K. acknowledges funding by the Fonds der Chemischen Industrie (Kekulé Mobility Fellowship).

\section{References}

1 W. Lubitz, H. Ogata, O. Ru and E. Reijerse, Hydrogenases, Chem. Rev., 2014, 114, 4081-4148.

2 P. M. Vignais and B. Billoud, Occurrence, classification, and biological function of hydrogenases: an overview, Chem. Rev., 2007, 107, 4206-4272.

3 S. T. Stripp and T. Happe, How Algae Produce Hydrogen - News from the Photosynthetic Hydrogenase, Dalton Trans., 2009, 9960-9969.

4 J. W. Peters, W. N. Lanzilotta, B. J. Lemon and L. C. Seefeldt, X-ray Crystal Structure of the Fe-Only Hydrogenase (CpI) 
from Clostridium pasteurianum to 1.8 Angstrom Resolution, Science, 1998, 282, 1853-1858.

5 A. S. Pandey, T. V. Harris, L. J. Giles, J. W. Peters and R. K. Szilagyi, Dithiomethylether as a ligand in the hydrogenase H-cluster, J. Am. Chem. Soc., 2008, 130, 4533-4540.

$6 \mathrm{~J}$. Esselborn, et al., A structural view of synthetic cofactor integration into [FeFe]-hydrogenases, Chem. Sci., 2016, 7, 959-968.

7 Y. Nicolet, C. Piras, P. Legrand, C. E. Hatchikian and J. C. Fontecilla-Camps, Desulfovibrio desulfuricans iron hydrogenase: the structure shows unusual coordination to an active site Fe binuclear center, Structure, 1999, 7, 13-23.

8 K. A. Vincent, A. Parkin and F. A. Armstrong, Investigating and exploiting the electrocatalytic properties of hydrogenases, Chem. Rev., 2007, 107, 4366-4413.

9 C. Greco, et al., Combining experimental and theoretical methods to learn about the reactivity of gas-processing metalloenzymes, Energy Environ. Sci., 2014, 7, 3543-3573.

10 F. A. Armstrong, et al., Guiding Principles of Hydrogenase Catalysis Instigated and Clarified by Protein Film Electrochemistry, Acc. Chem. Res., 2016, 49, 884-892.

11 J. C. Fontecilla-Camps, A. Volbeda, C. Cavazza and Y. Nicolet, Structure/function relationships of [NiFe]- and [FeFe]-hydrogenases, Chem. Rev., 2007, 107, 4273-4303.

12 J. Cohen, K. Kim, P. King, M. Seibert and K. Schulten, Finding gas diffusion pathways in proteins: application to $\mathrm{O}_{2}$ and $\mathrm{H}_{2}$ transport in $\mathrm{CpI}$ [FeFe]-hydrogenase and the role of packing defects, Structure, 2005, 13, 1321-1329.

13 G. Goldet, et al., Electrochemical kinetic investigations of the reactions of [FeFe]-hydrogenases with carbon monoxide and oxygen: comparing the importance of gas tunnels and active-site electronic/redox effects, J. Am. Chem. Soc., 2009, 131, 14979-14989.

14 J. C. Fontecilla-Camps, P. Amara, C. Cavazza, Y. Nicolet and A. Volbeda, Structure-function relationships of anaerobic gas-processing metalloenzymes, Nature, 2009, 460, 814-822.

15 C. Tard and C. J. Pickett, Structural and functional analogues of the active sites of the [Fe]-, [NiFe]-, and [FeFe]-hydrogenases, Chem. Rev., 2009, 109, 2245-2274.

16 T. R. Simmons, G. Berggren, M. Bacchi, M. Fontecave and V. Artero, Mimicking hydrogenases: from biomimetics to artificial enzymes, Coord. Chem. Rev., 2014, 270-271, 127-150.

17 F. Gloaguen and T. B. Rauchfuss, Small molecule mimics of hydrogenases: hydrides and redox, Chem. Soc. Rev., 2009, 38, 100-108.

18 A. Silakov, B. Wenk, E. Reijerse and W. Lubitz, ${ }^{14}$ N HYSCORE investigation of the $\mathrm{H}$-cluster of [FeFe] hydrogenase: evidence for a nitrogen in the dithiol bridge, Phys. Chem. Chem. Phys, 2009, 11, 6553-6554.

19 G. Berggren, et al., Biomimetic assembly and activation of [FeFe]-hydrogenases, Nature, 2013, 499, 66-69.

$20 \mathrm{~J}$. Esselborn, et al., Spontaneous activation of [FeFe]hydrogenases by an inorganic [2Fe] active site mimic, Nat. Chem. Biol., 2013, 9, 607-609.

21 A. J. Pierik, M. Hulstein, W. R. Hagen and S. P. Albracht, A low-spin iron with $\mathrm{CN}$ and $\mathrm{CO}$ as intrinsic ligands forms the core of the active site in [Fe]-hydrogenases, Eur. J. Biochem., 1998, 258, 572-578.

22 W. Roseboom, A. L. De Lacey, V. M. Fernandez, E. C. Hatchikian and S. P. J. Albracht, The active site of the [FeFe]hydrogenase from Desulfovibrio desulfuricans. II. Redox properties, light sensitivity and CO-ligand exchange as observed by infrared spectroscopy, JBIC, J. Biol. Inorg. Chem., 2006, 11, 102-118.

23 D. W. Mulder, et al., EPR and FTIR Analysis of the Mechanism of $\mathrm{H} 2$ Activation by [FeFe]-Hydrogenase HydA1 from Chlamydomonas reinhardtii, J. Am. Chem. Soc., 2013, 135, 6921-6929.

24 B. J. Lemon and J. W. Peters, Binding of Exogenously Added Carbon Monoxide at the Active Site of the Iron-Only Hydrogenase (CpI) from Clostridium pasteurianum, Biochemistry, 1999, 38, 12969-12973.

25 A. L. De Lacey, C. Stadler, C. Cavazza, E. C. Hatchikian and V. M. Fernandez, FTIR Characterization of the Active Site of the Fe-hydrogenase from Desulfovibrio desulfuricans, J. Am. Chem. Soc., 2000, 122, 11232-11233.

26 Y. Nicolet, et al., Crystallographic and FTIR spectroscopic evidence of changes in Fe coordination upon reduction of the active site of the Fe-only hydrogenase from Desulfovibrio desulfuricans, J. Am. Chem. Soc., 2001, 123, 1596-1601.

27 Z. Chen, et al., Infrared Studies of the CO-Inhibited Form of the Fe-Only Hydrogenase from Clostridium pasteurianum I: Examination of Its Light Sensitivity at Cryogenic Temperatures, Biochemistry, 2002, 41, 2036-2043.

$28 \mathrm{M}$. Senger, et al., Stepwise isotope editing of [FeFe]-hydrogenases exposes cofactor dynamics, Proc. Natl. Acad. Sci. U. S. A., 2016, 113, 8454-8459.

29 A. Adamska-Venkatesh, et al., New redox states observed in [FeFe] hydrogenases reveal redox coupling within the H-cluster, J. Am. Chem. Soc., 2014, 136, 11339-11346.

30 C. Lambertz, et al., Electronic and molecular structures of the active-site $\mathrm{H}$-cluster in [FeFe]-hydrogenase determined by site-selective X-ray spectroscopy and quantum chemical calculations, Chem. Sci., 2014, 5, 1187-1203.

31 C. Sommer, et al., Proton Coupled Electronic Rearrangement within the H-Cluster as an Essential Step in the Catalytic Cycle of [FeFe] Hydrogenases, J. Am. Chem. Soc., 2017, 139, 1440-1443.

32 A. Adamska-Venkatesh, et al., Identification and characterization of the 'super-reduced' state of the H-cluster in [FeFe] hydrogenase: a new building block for the catalytic cycle?, Angew. Chem., 2012, 51, 11458-11462.

33 P. Chernev, et al., Hydride Binding to the Active Site of -Hydrogenase, Inorg. Chem., 2014, 53, 12164-12177.

34 S. Mebs, et al., Bridging Hydride at Reduced H-Cluster Species in [FeFe]-Hydrogenases Revealed by Infrared Spectroscopy, Isotope Editing, and Quantum Chemistry, J. Am. Chem. Soc., 2017, 139, 12157-12160.

35 B. E. Barton, M. T. Olsen and T. B. Rauchfuss, Aza- and oxadithiolates are probable proton relays in functional models for the [FeFe]-hydrogenases, J. Am. Chem. Soc., 2008, 130, 16834-16835. 
36 W. Wang, et al., Crystallographic characterization of a fully rotated, basic diiron dithiolate: model for the H(red) state?, Chemistry, 2013, 19, 15476-15479.

37 D. W. Mulder, et al., Investigations on the Role of ProtonCoupled Electron Transfer in Hydrogen Activation by [FeFe]hydrogenase, J. Am. Chem. Soc., 2014, 136, 15394-15402.

38 D. W. Mulder, Y. Guo, M. W. Ratzloff and P. W. King, Identification of a Catalytic Iron-Hydride at the H-Cluster of [FeFe]-Hydrogenase, J. Am. Chem. Soc., 2016, 139, 83-86.

39 E. J. Reijerse, et al., Direct Observation of an Ironbound Terminal Hydride in [FeFe]-Hydrogenase by Nuclear Resonance Vibrational Spectroscopy, J. Am. Chem. Soc., 2017, 139, 4306-4309.

40 M. Winkler, et al., Accumulating the hydride state in the catalytic cycle of [FeFe]-Hydrogenases, Nat. Commun., 2017, 8, 1-7.

41 V. Fourmond, et al., The oxidative inactivation of FeFe hydrogenase reveals the flexibility of the H-cluster, Nat. Chem., 2014, 6, 336-342.

42 C. Greco, M. Bruschi, L. De Gioia and U. Ryde, A QM/MM Investigation of the Activation and Catalytic Mechanism of Fe-only Hydrogenases, Inorg. Chem., 2007, 46, 15-16.

43 G. Filippi, F. Arrigoni, L. Bertini, L. De Gioia and G. Zampella, DFT Dissection of the Reduction Step in H2 Catalytic Production by [FeFe]-Hydrogenase-Inspired Models: Can the Bridging Hydride Become More Reactive Than the Terminal Isomer?, Inorg. Chem., 2015, 54, 9529-9542.

44 M. Bruschi, P. Fantucci and L. De Gioia, Density functional theory investigation of the active site of Fe-hydrogenases. systematic study of the effects of redox state and ligands hardness on structural and electronic properties of complexes related to the $[2 \mathrm{Fe}](\mathrm{H})$ subcluster, Inorg. Chem., 2004, 43, 3733-3741.

45 A. K. Justice, et al., Chelate control of diiron(I) dithiolates relevant to the [Fe-Fe]-hydrogenase active site, Inorg. Chem., 2007, 46, 1655-1664.

46 S. P. J. Albracht, W. Roseboom and E. C. Hatchikian, The active site of the [FeFe]-hydrogenase from Desulfovibrio desulfuricans. I. Light sensitivity and magnetic hyperfine interactions as observed by electron paramagnetic resonance, JBIC, J. Biol. Inorg. Chem., 2006, 11, 88-101.

47 C. Kamp, et al., Isolation and first EPR characterization of the [FeFe]-hydrogenases from green algae, Biochim. Biophys. Acta, 2008, 1777, 410-416.

48 B. Bennett, B. J. Lemon and J. W. Peters, Reversible carbon monoxide binding and inhibition at the active site of the Fe-only hydrogenase, Biochemistry, 2000, 39, 7455-7460.

49 S. Katz, et al., Vibrational spectroscopy reveals the initial steps of biological hydrogen evolution, Chem. Sci., 2016, 7, 6746-6752.

50 P. Knörzer, et al., Importance of the protein framework for catalytic activity of [FeFe]-hydrogenases, J. Biol. Chem., 2012, 287, 1489-1499.

51 S. Morra, et al., Site Saturation Mutagenesis Demonstrates a Central Role for Cysteine 298 as Proton Donor to the Catalytic Site in CaHydA [FeFe]-Hydrogenase, PLoS One, 2012, 7, e48400.
52 M. Winkler, J. Esselborn and T. Happe, Molecular basis of [FeFe]-hydrogenase function: an insight into the complex interplay between protein and catalytic cofactor, Biochim. Biophys. Acta, 2013, 1827, 974-985.

53 A. J. Cornish, K. Gärtner, H. Yang, J. W. Peters and E. L. Hegg, Mechanism of proton transfer in [FeFe]-Hydrogenase from Clostridium pasteurianum, J. Biol. Chem., 2011, 19, 38341-38347.

54 B. Ginovska-Pangovska, et al., Molecular dynamics study of the proposed proton transport pathways in [FeFe]-hydrogenase, Biochim. Biophys. Acta, 2014, 1837, 131-138.

55 A. J. Cornish, et al., Single-Amino Acid Modifications Reveal Additional Controls on the Proton Pathway of [FeFe]Hydrogenase, Biochemistry, 2016, 55, 3165-3173.

56 J. Noth, et al., [FeFe]-Hydrogenase with Chalcogenide Substitutions at the H-Cluster Maintains Full H2 Evolution Activity, Angew. Chem., 2016, 55, 8396-8400.

57 E. C. Hatchikian, N. Forget, V. M. Fernandez, R. Williams and R. Cammack, Further characterization of the [Fe]hydrogenase from Desulfovibrio desulfuricans ATCC 7757, Eur. J. Biochem., 1992, 209, 357-365.

58 M. Mirmohades, et al., Following [FeFe] Hydrogenase Active Site Intermediates by Time-Resolved Mid-IR Spectroscopy, J. Phys. Chem. Lett., 2016, 7, 3290-3293.

59 B.-J. Schultz, H. Mohrmann, V. A. Lorenz-fonfria and J. Heberle, Protein dynamics observed by tunable mid-IR quantum cascade lasers across the time range from 10 ns to 1 s, Spectrochim. Acta, Part A, 2017, DOI: 10.1016/ j.saa.2017.01.010.

60 B. L. Greene, G. J. Schut, M. W. W. Adams and R. B. Dyer, Pre-Steady-State Kinetics of Catalytic Intermediates of an [FeFe]-Hydrogenase, ACS Catal., 2017, 7, 2145-2150.

61 J. P. Perdew, Density-functional approximation for the correlation energy of the inhomogeneous electron gas, Phys. Rev. B: Condens. Matter Mater. Phys., 1986, 33, 8822-8824.

62 A. Becke, Density-Functional Exchange-Energy Approximation With Correct Asymptotic-Behavior, Phys. Rev. A: At., Mol., Opt. Phys., 1988, 38, 3098-3100.

63 A. Schäfer, C. Huber and R. Ahlrichs, Fully optimized contracted Gaussian basis sets of triple zeta valence quality for atoms Li to Kr, J. Chem. Phys., 1994, 100, 5829-5835.

64 M. J. Frisch, et al., Gaussian 09, 2009, DOI: 10.1017/ CBO9781107415324.004.

65 G. von Abendroth, et al., Optimized over-expression of [FeFe] hydrogenases with high specific activity in Clostridium acetobutylicum, Int. J. Hydrogen Energy, 2008, 33, 6076-6081.

66 J. F. Siebel, et al., Hybrid [FeFe]-Hydrogenases with Modified Active Sites Show Remarkable Residual Enzymatic Activity, Biochemistry, 2015, 54, 1474-1483.

67 W. J. Lem and M. Wayman, Decomposition of aqueous dithionite. Part I. Kinetics of decomposition of aqueous sodium dithionite, Can. J. Chem., 1970, 48, 776-781.

68 M. Wayman and W. J. Lem, Decomposition of aqueous dithionite. Part II. A reaction mechanism for the decomposition of aqueous sodium dithionite, Can. J. Chem., 1970, 48, 782-787. 
69 M. Birringer, S. Pilawa and L. Flohé, Trends in selenium biochemistry, Nat. Prod. Rep., 2002, 19, 693-718.

70 H. J. Reich and R. J. Hondal, Why Nature Chose Selenium, ACS Chem. Biol., 2016, 11, 821-841.

71 H. Abul-Futouh, M. El-khateeb, H. Görls, K. J. Asali and W. Weigand, Selenium makes the difference: protonation of [FeFe]-hydrogenase mimics with diselenolato ligands, Dalton Trans., 2017, 46, 2937-2947.

72 U. P. Apfel, et al., Models for the active site in [FeFe] hydrogenase with iron-bound ligands derived from bis-, tris-, and tetrakis(mercaptomethyl)silanes, Inorg. Chem., 2010, 49, 10117-10132.

73 R. Zaffaroni, T. B. Rauchfuss, D. L. Gray, L. De Gioia and G. Zampella, Terminal vs. bridging hydrides of diiron dithiolates: protonation of $\mathrm{Fe}_{2}$ (dithiolate) $(\mathrm{CO})_{2}\left(\mathrm{PMe}_{3}\right)_{4}$, J. Am. Chem. Soc., 2012, 134, 19260-19269.

74 Y.-C. Liu, K.-T. Chu, R.-L. Jhang, G.-H. Lee and M.-H. Chiang, [FeFe] hydrogenase active site modeling: a key intermediate bearing a thiolate proton and Fe hydride, Chem. Commun., 2013, 49, 4743-4745.

75 V. A. Lórenz-Fonfría, V. Muders, R. Schlesinger and J. Heberle, Changes in the hydrogen-bonding strength of internal water molecules and cysteine residues in the conductive state of channelrhodopsin-1, J. Chem. Phys., 2014, 141, 22 D507.

76 A. Alwaaly and R. A. Henderson, Unexpected explanation for the enigmatic acid-catalysed reactivity of [Fe4S4X4]2-clusters, Chem. Commun., 2014, 50, 4799-4802.

77 L. Yu, et al., Targeting intermediates of [FeFe]-hydrogenase by CO and CN vibrational signatures, Inorg. Chem., 2011, 50, 3888-3900.

78 H. Beinert, R. H. Holm and E. Münck, Iron-Sulfur Clusters: Nature's Modular, Multipurpose Structures, Science, 1997, 277, 653-659.

79 D. C. Johnson, D. R. Dean, A. D. Smith and M. K. Johnson, Structure, function, and formation of biological iron-sulfur clusters, Annu. Rev. Biochem., 2005, 74, 247-281.
80 C. T. Saouma, W. D. Morris, J. W. Darcy and J. M. Mayer, Protonation and Proton-Coupled Electron Transfer at S-Ligated [4Fe-4S] Clusters, Chemistry, 2015, 21, 9256-9260.

81 R. A. Henderson, Mechanistic Studies on Synthetic Fe-S-based Clusters and Their Relevance to the Action of Nitrogenases, Chem. Rev., 2005, 105, 2365-2437.

82 R. A. Henderson, Proton transfer to synthetic Fe-S-based clusters, Coord. Chem. Rev., 2005, 249, 1841-1856.

83 C. Fichtner, M. van Gastel and W. Lubitz, Wavelength dependence of the photo-induced conversion of the Ni-C to the $\mathrm{Ni}-\mathrm{L}$ redox state in the $[\mathrm{NiFe}]$ hydrogenase of Desulfovibrio vulgaris Miyazaki F, Phys. Chem. Chem. Phys., 2003, 5, 5507-5513.

84 M. Kampa, M. E. Pandelia, W. Lubitz, M. Van Gastel and F. Neese, A metal-metal bond in the light-induced state of [NiFe] hydrogenases with relevance to hydrogen evolution, J. Am. Chem. Soc., 2013, 135, 3915-3925.

85 E. Siebert, et al., Resonance Raman Spectroscopy as a Tool to Monitor the Active Site of Hydrogenases, Angew. Chem., 2013, 52, 5162-5165.

86 B. L. Greene, C. Wu, G. E. Vansuch, M. W. W. Adams and R. B. Dyer, Proton Inventory and Dynamics in the Ni-S to Ni-C Transition of a [NiFe] Hydrogenase, Biochemistry, 2016, 55, 1813-1825.

87 D. W. Mulder, et al., Stepwise [FeFe]-hydrogenase H-cluster assembly revealed in the structure of $\operatorname{HydA}(\Delta \mathrm{EFG})$, Nature, 2010, 465, 248-251.

88 S. Y. Reece and D. G. Nocera, Proton-coupled electron transfer in biology: results from synergistic studies in natural and model systems, Annu. Rev. Biochem., 2009, 78, 673-699.

89 J. L. Dempsey, J. R. Winkler and H. B. Gray, Proton-coupled electron flow in protein redox machines, Chem. Rev., 2010, 110, 7024-7039.

90 S. Hammes-Schiffer, Proton-Coupled Electron Transfer: Moving Together and Charging Forward, J. Am. Chem. Soc., 2015, 137, 8860-8871. 